\title{
APORTES MORFOTAXONOMICOS EN EL GENERO Aspergillus Link: CLAVES PARA LAS ESPECIES AMBIENTALES Y CLINICAS MAS COMUNES
}

\author{
(Morphotaxonomic contributions in the genus Aspergillus Link: \\ keys for the most common environmental and clinical species)
}

Palabras clave: Aspergillus, claves especies comunes. Key words: Aspergillus, key common species.

Eduardo Piontelli L.

Universidad de Valparaíso, Escuela de Medicina, Cátedra de Micología, Casilla 92 V, Valparaíso Chile eduardo.piontelli@uv.cl

\section{RESUMEN}

Se condensan los principales alcances en el género Aspergillus y las metodologías de diagnóstico morfo-taxonómico de las especies más comunes de utilidad para el micólogo en áreas clínicas y ambientales. Se aporta información bibliográfica actualizada para las determinaciones polifásicas de las especies y algunas claves morfofisiológicas tentativas en ciertos taxa de importancia médica, con énfasis en la Sección Fumigati.

\section{INTRODUCCION}

Las especies de Aspergillus Link, se consideran entre los organismos de más amplia distribución cosmopolita, capaces de colonizar una gran variedad de substratos en los diferentes nichos ecológicos del suelo; en general, son frecuentes en climas tropicales y subtropicales pero disminuyen en los climas fríos, mientras algunas epecies son restringidas a hábitat específicos. Se consideran contaminantes comunes de varios substratos, en especial alimentos, granos, suelos (salinos, cultivados, desérticos y de pastoreo), bosques subtropicales deciduos y ambientes internos, entre otros.

Un buen número de sus integrantes tiene importancia ecológica, genética, biotecnológica, sin olvidar sus aspectos patogénicos y micotoxicogénicos relacionados con el hombre y otros mamíferos (Powell et al., 1994).

Se reconoce a Link (1809) como al autor que validó al género (CINB), a pesar que Micheli (1729) fue el primero que lo describió. En el siglo XX se publicaron varias monografias del género (Thom \& Church, 1926;

Recibido el 1 de Septiembre 2008

Aceptado el 28 de Noviembre 2008

\section{ABSTRACT}

The main information about the Aspergillus genus together with methodologies for the morphotaxonomic diagnosis of the most common species useful for the mycologist in clinical and environmental areas are here condensed. An updated bibliography is forwarded in order to carry out polyphasic identification of the species as well as tentative morphophysiological keys in some taxa having medical significance with emphasis in Section Fumigati.

Thom \& Raper, 1945), pero la más completa en su época y aún consultada fue la escrita por Raper \& Fennel en el año 1965, que incluyó varias nuevas especies; sin embargo, a pesar de incluir la diagnosis latina de las nuevas especies, no designaron las especies tipo, describiendo además los teleomorfos bajo el mismo nombre de los anamorfos (Aspergillus). Los aportes posteriores fueron agregando nuevas especies y reordenaron el género hacia una línea más acorde al Código Internacional de Nomenclatura Botánica (CINB) dilucidando sus relaciones con los teleomorfos de Aspergillus. Las nuevas especies descritas desde 1965 fueron publicadas en la literatura por Samson $(1979,1992$, 1993, 2000) y otros autores (Al Musallan, 1980; Christensen, 1981-1982, entre otros), aportándose al mimo tiempo varios métodos de identificación.

La taxonomía tradicional del género se basa principalmente en sus caracteres fenotípicos y fisiológicos, los cuales han aportado satisfactorias delimitaciones de las especies, sin embargo, existen variaciones morfológicas en varias secciones que han llevado a controversias en sus esquemas taxonómicos. En el nuevo siglo 21, Aspergillus y sus teleomorfos han sido recientemente investigados con métodos polifásicos (morfológicos, fisiológicos y moleculares) para examinar 


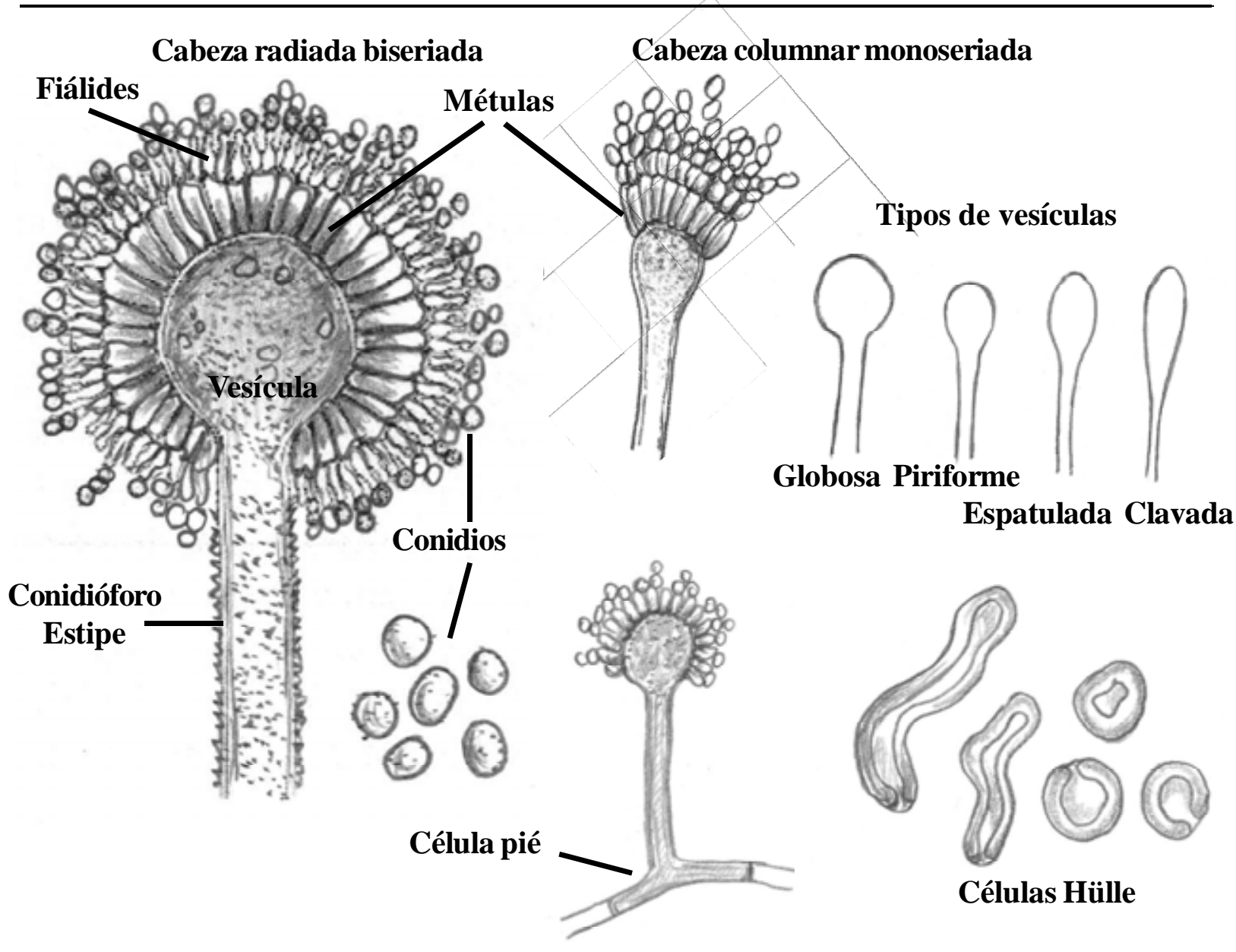

Figura 1. Estructuras morfológicas en el género Aspergillus: cabezas radiadas y colomnares, tipos de vesículas, célula pie, células Hülle

la variabilidad entre sus especies (Samson \& Pitt, 2000; Samson et al, 2006; Samson \& Vargas, 2007).

Las especies de Aspergillus se estudian mediante sus características macro y micromorfológicas, junto a caracteres de crecimiento en diferentes medios de cultivo, perfiles de extrolitos (micotoxinas) y técnicas moleculares, tales como; secuencias del gen de la b-tubulina, calmodulina y actina, mientras otras técnicas de análisis como, amplificación de DNA polimórfico al azar (RAPD) entre otras, han sido utilizadas (Geiser et al., 2000-2004 -2007; Balajee et al., 2005; Pringle et al., 2005; Samson et al., 2007; Varga et al., 2007)

En clínica, los análisis moleculares e inmunológicos han sido un avance prometedor en el diagnóstico rápido, sin embargo, la microscopía y los cultivos (con un adecuado entrenamiento profesional), siguen siendo las herramientas esenciales no solo en este campo, sino en muchos otros (McClenny, 2005).

Las secciones de Aspergillus Fumigati, Circumdati, Flavi y Nigri, contienen los más importantes patógenos humanos, sin embargo, A. fumigatus fue considerado como el único y más importante Aspergillus patogénico conocido dentro de la Sección Fumigati, una situación que ha cambiado recientemente con reportes clínicos que incluyen, Neosartorya pseudofis- cheri, A. lentulus (resistente a múltiples antifúngicos) y A. undagawe (Neosartorya) como patógenas relacionadas con A. fumigatus (Balajee et al.,2005). Los estudios moleculares han revelado frecuentes errores en la identificación de $\boldsymbol{A}$. fumigatus cuando se usa solamente la morfología, sin otros datos fisiológicos de apoyo, especialmente en cepas de baja esporulación (Balajee et al., 2006).

\section{b) Características macroscópicas.}

Estas son importantes en la clasificación subgenérica, tales como el color de los conidios, que se observa en placas de Petri en los diferentes medios de cultivo (debido a su utilidad en la clasificación subgenérica); el color puede variar desde el negro, blanco, amarillo, ocre, azul verde, o una mezcla de ellos, por lo que es recomendable emplear a veces una tabla de colores determinada. Las colonias pueden producir gotas de líquidos en su superficie, ya sea incoloras o con diferentes tonalidades, así como pigmentos de varios colores en el reverso de la colonia, si éstos son solubles difunden al agar. El diámetro de las colonias (en $\mathrm{mm}$ ), es otra característica fisiológica útil, debido a que las especies del género pueden variar en su habilidad de crecer a diferentes potenciales de agua, y a 
diferentes temperaturas en medios estandarizados.

Algunas especie pueden producir en los cultivos estructuras de variado tamaño, pero observables a simple vista o bajo la lupa estereoscópica, de aspecto generalmente redondo, de diversos colores y consistencia firme, llamadas esclerocios (Sección: Candidi, Circumdati, Flavi, Nigri), pero también pueden presentarse cleistotecios (ascomata), principalmente de los géneros Eurotium, Neosartorya y Emericella).

\section{c) Características microscópicas}

Aspergillus es un género anamórfico que produce esporas asexuales (conidios, mitosporas) sobre estructuras especializadas características que se componen de un: conidióforo (estipe) que se dilata en el ápice, formando una vesícula de diferentes formas (Fig. 1). Las vesículas pueden variar en tamaño y forma, desde esféricas (globosas), clavadas, piriformes y espatuladas. La vesícula nace sobre un corto o largo pie, usualmente aseptado, liso o rugoso y que se une a la hifa portadora generalmente en ángulo recto mediante
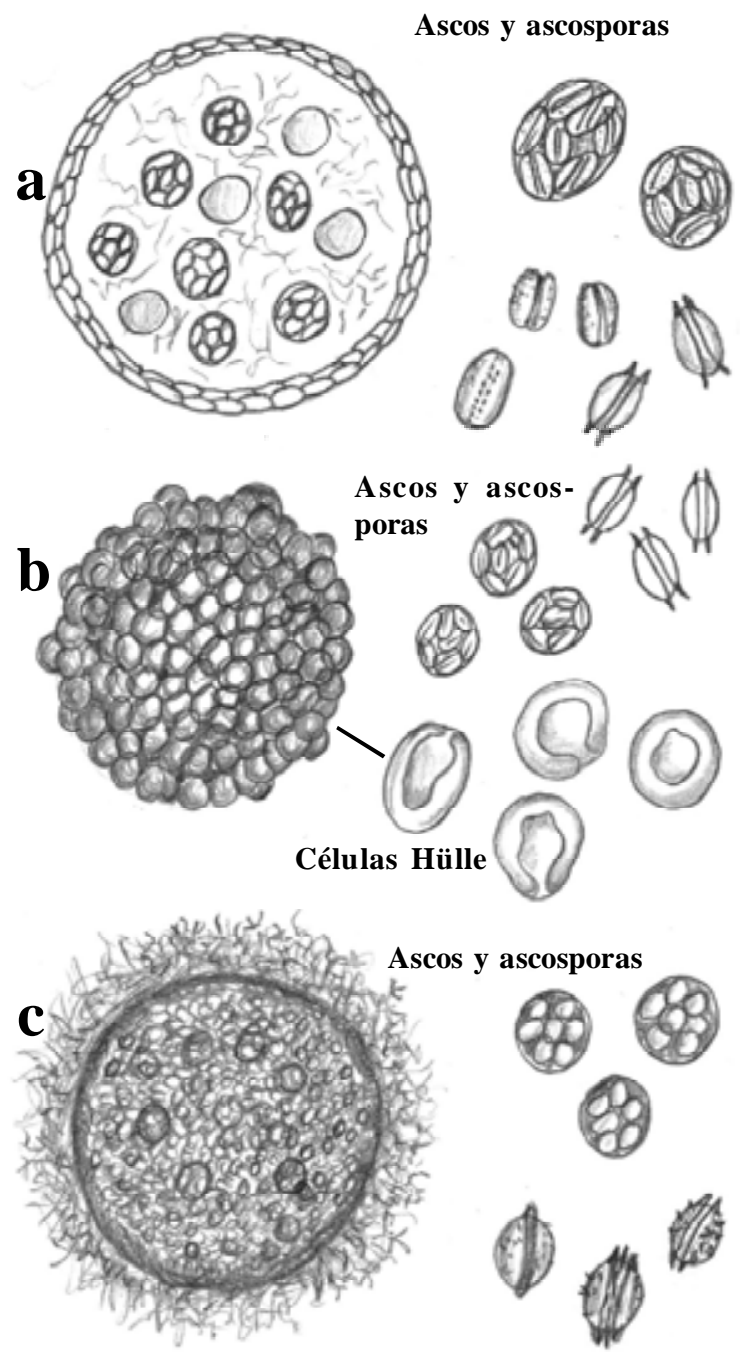

Figura 2. Principales tipos de ascomata en teleomorfos de Aspergillus.

a) Eurotium, b) Emericella, c) Neosartorya. una estructura en forma de $\mathrm{T}$ invertida llamada célula pie (Fig. 1), que forma parte integral del estipe. La célula pie y el estipe son comúnmente llamados conidióforos, que apicalmente terminan siempre en una vesícula dilatada, la cual puede dar origen en su superficie a 1 o 2 tipos de estructuras ya sea en una sola alineación de fiálides (monoseriados o uniseriados), que son las célula conidiógenas, que originan siempre conidios secos o presentar una segunda estructura bajo las fiálides llamadas métulas (biseriadas) que pueden sostener 1 a 10 fiálides c/u (Fig.1). Algunos taxa pueden ser monoseriados y biseriados a la vez, mientras otros son estrictamente monoseriados o biseriados. Ambas estructuras (fiálides y métulas) se forman sincrónicamente en la superficie de la vesícula pudiéndola cubrir parcial o totalmente. Las vesículas, fíalides y métulas (si estas últimas están presentes), junto con los conidios, forman lo que llamamos cabeza conidial, la cual por la disposición de los conidios puede ser de aspecto columnar o radiado (redonda). Pueden presentarse situaciones intermedias, como columnar laxa, que forma varias columnas divergentes o radiada laxa, con cortas columnas que abren la cabeza radiada, pero mantienen el aspecto redondo. Algunos miembros del género pueden producir células de gruesa pared y de variado tamaño (siempre mayores que los conidios o mitosporas), llamadas células de Hülle, generalmente entremezcladas con el micelio o asociadas a las formas sexuales del género (ej.Cleistotecios de Emericella). Si bien es cierto que su función parece ser protectiva, pueden actuar también como propágalos de dispersión.

\section{d) Presencia de teleomorfo.}

Algunos miembros del género son capaces de reproducirse sexualmente en cultivos mediante la formación de cleistotecios (Ascomycota, Pezizomycotina, Eurotiomycetes, Trichocomaceae), que contienen ascosporas formadas en ascos más o menos redondos, evanescentes, dispuestos desordenadamente en el centrum. El tipo de ascoma, tamaño, forma, estructura, superficie y color de las ascosporas, son importantes en la determinación de los taxa. Actualmente se consideran 11 géneros teleomórficos dentro del género anamórfico Aspergillus y sus subgéneros (Tabla 1).

Chaetosartoria (Sección Cremei)

Dichlaena y Eurotium (Sección Aspergillus, Fig. 2a)

Emericella (Sección Nidulantes, Fig. 2b)

Fennellia (Sección Flavipedes),

Hemicarpenteles, Sclerocleista y Warcupiella (Sección Ornati),

Neopetromyces (Seccion Circumdati), Neosartorya (Sección Fumigati, Fig. 2c), Petromyces (Sección Flavi).

\section{e) Producción de Micotoxinas}

Los Aspergillus no se han considerado como causa de enfermedades en las plantas, sin embargo, algunas especies son responsables de algunos proble- 
Tabla 1. Nomenclatura de los taxa infragenéricos del género Aspergillus y sus Secciones (Modificada de Gams et al., 1985 y Klich, 2002).

\section{Subgénero \\ Aspergillus}

Uniseriados, xerofílicos, conidios gris-verdosos

\section{Fumigati}

Uniseriados, vesículas pre-

dominantemente piriformes,

conidios gris-verdes, azul-verde a naranja

\section{Ornati}

Uniseriados, conidios gris verdosos,

amarillo-verdosos u oliva-café

\section{Clavati}

Uniseriados, vesículas clavadas,

conidios gris-verdosos

\section{Nidulantes}

Biseriados, conidios de colores variables

\section{Circumdati}

Uni o biseriado, vesículas esféricas o piriformes

$$
\text { os, }
$$

Ornati (A. ornatus grupo)

\section{Secciones*}

Aspergillus (A. glaucus grupo). Teleomorfo Eurotium, cleistotecios amarillos

Restricti (A. restrictus grupo). Crecimiento lento en los medios

Fumigati (A. fumigatus grupo). Conidios gris verde a azul verdosos Cervini (A. cervinus grupo). Conidios naranja claros a gris naranja

Clavati (A. clavatus grupo) (Incluida en Fumigati por Peterson, 2008)

Nidulantes ( A. nidulans grupo). Estipe corto cafesoso, células Hülle a menudo presentes. Teleomorfo Emericella, ascosporas rojo púrpura. Versicolor (A. versicolor grupo). Estipe hialino a café, conidios verdes, verde grises o azul verdosos. (Incluida en Nidulantes por Peterson 2008). Usti (A. ustus grupo). Estipe café, conidios café a oliva, rugosos. Terrei (A. terreus grupo). Estipe hialino, conidios naranja café a ante. Flavipedes (A. flavipes grupo). Estipe hialino a café claro, conidios blancos a crema.

Wentii (A. Wentii grupo).Conidios color ante, amarillo-café o oliva-café. Flavi (A. Flavus grupo). Estipe rugoso, conidios amarillo verde a oliva-cafè . Nigri (A. niger grupo). Estipe liso, conidios oscuros cercanos al negro. Circumdati (A. ochraceus grupo).Predominantemente biseriados, conidios amarillos, ante u ocráceos.

Candidi (A. candidus grupo). Conidios blancos o cercanos al blanco.

Cremei (A. cremeus grupo). Conidios café, amarillos o azul verdosos. Sparsi (A. sparsus grupo).Conidios gris pálido a oliva-ante.

\section{(especies que forman sinnemata) \\ Ochraceoreosei (A.ochraceoroseus y A.rambelli). \\ Ochracxeoroseus}

Biseriados, vesícula redonda, conidios gris-amarillentos (Frisvald et al., 2005) incluyen ambas especies bajo el subgénero Circumdati, por su incapacidad de crecer a $37^{\circ} \mathrm{C}$ y sus extrolitos)

(*La resoloción filogenética limitada de algunas especies y secciones aconseja el uso de más genes adicionales para determinar sus relaciones).

mas de contaminación en productos vegetales ya sea en precosecha, cosecha, post cosecha y almacenamiento (A. niger, A. flavus, A. parasiticus, A. ochraceus, A. carbonarius, A. alliaceus, entre otros)( Perrone et al., 2007).

El mayor problema reside en la presencia de micotoxinas contaminantes en alimentos y piensos. donde varias de estas se han identificado y la más importante son las aflatoxinas y la ocratoxina A (Vargas et al., 2004). Las aflatoxinas B1, B2, G1 y G2, por su poder carcinogénico son consideradas las más hepatotóxicas (Bennet \& Klich, 2003), por el riesgo en salud humana y animal, debido a la contaminación de productos en precosecha: maíz, algodón, soja, maní, nueces y por ciertos residuos que aparecen en la leche debido al consumo por los animales de piensos contaminados. La ocratoxina A es una potente nefrotoxina que además posee propiedades carcinogénicas, teratogénicas e inmunotóxicas en ratas y posiblemente en humanos. Puede contaminar alimentos, tales como granos, legumbres, café, frutas secas, cerveza, vino y carnes: las especies más productoras pertenecen a la sección Circumdati y Nigri (Ver Frisvald et al., 2007). 
Tabla 2. Aspergillus productores de Aflatoxinas y sus extrolitos quelantes ( Frisvald et al., 2005)

\begin{tabular}{|c|c|c|c|c|c|}
\hline \multirow[t]{2}{*}{ Especies } & \multicolumn{2}{|c|}{$\begin{array}{l}\text { Aflatoxi- } \\
\text { nas }\end{array}$} & \multirow{2}{*}{$\begin{array}{c}\text { Acido } \\
\text { Cyclopia- } \\
\text { zónico }\end{array}$} & \multirow{2}{*}{$\begin{array}{l}\text { Acido } \\
\text { Kojico }\end{array}$} & \multirow{2}{*}{$\begin{array}{c}\text { Acido } \\
\text { Asper- } \\
\text { gílico }\end{array}$} \\
\hline & $\mathbf{B}_{1}$ & $\mathbf{G}_{1}$ & & & \\
\hline \multicolumn{6}{|c|}{ Aspergillus sección Flavi (Petromyces) } \\
\hline A. bombycis & + & + & - & + & - \\
\hline A. flavus & + & - & + & + & + \\
\hline A. nomius & + & + & - & + & + \\
\hline A. parasiticus & + & + & - & + & + \\
\hline A. parvisclerotigenus & + & \pm & + & + & + \\
\hline A. pseudotamarii & + & - & + & + & - \\
\hline A. toxicarius & + & + & - & + & + \\
\hline \multicolumn{6}{|c|}{ Aspergillus subgénero Nidulantes (Emericella) } \\
\hline E. astellata & + & - & - & - & - \\
\hline E. sp. IBT 21903 & + & - & - & - & - \\
\hline E. venezuelensis & + & - & - & - & - \\
\hline \multicolumn{6}{|c|}{ Aspergillus sección Ochraceorosei } \\
\hline A. ochraceoroseus & + & - & - & - & - \\
\hline A. rambellii & + & - & - & - & - \\
\hline
\end{tabular}

\section{f) Presencia de extrolitos.}

La detección de la presencia de extrolitos (compuestos químicos), ha sido otro buen aporte en la determinación de las especies, demostrándose que cada aislamiento de Aspergillus presenta un específico perfil que agrega una importante información para la presencia de micotoxinas (Tabla 2). Los extrolitos se analizan mediante el método de HPLC (diode array detection) (Frisvald \& Thrane,1993) modificado por Smedsgaard (1997), retenciones de índices de alquilfenona y detección de una matriz de diodo UV-VIS.

\section{g) Subgéneros y Secciones de Aspergillus.}

Enla Tabla 1, los nombres de los grupos según la antigua clasificación de Raper \& Fennell (1965), están entre paréntesis. Como los grupos no tienen un estatus bajo el Código Internacional de Nomenclatura Botánica (ICBN), se han reemplazado por los nombres de subgéneros y Secciones (Gams et al., 1985).

La posición de algunas especies y la existencia de otros subgéneros y secciones ha sido cuestionada y modificada por ciertos autores (Kozakievicz, 1989).

Peterson (2000), propone eliminar 3 de los subgéneros establecidos por Gams et al. (1985), y retener 12 de las 18 secciones, modificar 3 y eliminar 3; Peterson et al. (2008), con nuevos datos moleculares proponen 8 subgéneros y 22 secciones. Posteriormente Peterson (2008), agrega nuevos cambios en un análisis de secuencias de DNA desde 4 locus. La Tabla 1, mantiene la estructura clásica con algunas modificaciones.*

\section{h) Medios de cultivo para la identificación de las} especies de Aspergillus.

Se emplean por lo general 3 a 5 medios de cultivo

1.- CYA25, Agar Czapek extracto de levadura a $25^{\circ} \mathrm{C}$ por 7 días.

2.- CYA37. Agar Czapek extracto de levadura a

\section{$37^{\circ} \mathrm{C}$ por 7 días}

3.-CY20S. Agar Czapek extracto de levadura más $20 \%$ de sacarosa a $25^{\circ} \mathrm{C}$ por 7 días (para las especies xerofílicas (sección Aspergillus (Eurotium) y sección Restricti).

4. MEA. Agar extracto de malta a $25^{\circ} \mathrm{C}$ por 7 días.

5. CZ. Agar Czapek a $25^{\circ} \mathrm{C}$ por 7 días. Es un medio considerado viejo estandar que aún se emplea en muchos laboratorios y textos y al cual se le agregan trazas de metales como el $\mathrm{Zn} \mathrm{y} \mathrm{Cu}$, cuando el medio no los posee en su fórmula.

Para cada cultivo, se emplean por lo general 4 placas de Petri de $100 \mathrm{~mm}$ a las cuales se le agregan $25 \mathrm{ml}$ de cada medio de cultivo CYA25, CYA37 (o a más temperatura si es necesario), CYA20S y MEA25. Es importante la profundidad del medio, debido a que la menor o mayor profundidad puede llevar a ciertos cambios morfológicos (Okuda et al., 2000).

Las placas con sus diferentes medios deben inocularse en 3 puntos equidistantes del centro mediante una solución de conidios disueltos en un medio con $0,2 \%$ de agar y $0,05 \%$ de Twen 80 (Pitt \& Hockin, 1997). Los conidios del cultivo a analizar, se mezclan en 1 o 2 cc del medio y mediante una micropipeta se depositan $2 \mu \mathrm{L}$ en 3 puntos equidistantes de las placas.

\section{I) Identificación rápida de las especies aflatoxigénicas de Aspergillus.}

Un medio especial para la identificación rápida de potenciales Aspergillus aflatoxigénicos (A. flavus y A.parasiticus) en 3 días, es el agar AFPA (Aspergillus Flavus y Parasiticus Agar) (Pitt et al.,1983). Existen otros medios para distinguir algunas especies de la sección Flavi (Ver Samson et al., 2004), pero la identificación en medios estandar es suficiente para el micólogo con experiencia.

\section{J) Medios de cultivo y fórmulas}

1.- Concentrado de Czapek (con trazas de metales)

$\begin{array}{lr}\mathrm{NaNO}_{3} & 30 \mathrm{~g} \\ \mathrm{KCl} & 5 \mathrm{~g} \\ \mathrm{MgSO} 4.7 \mathrm{H}_{2} \mathrm{O} & 5 \mathrm{~g} \\ \mathrm{FeSO} 4 . \mathrm{TH}_{2} \mathrm{O} & 0,1 \mathrm{~g} \\ \mathrm{ZnSO} 4 . \mathrm{TH}_{2} \mathrm{O} & 0,1 \mathrm{~g} \\ \mathrm{CuSO} 4.5 \mathrm{H}_{2} \mathrm{O} & 0,1 \mathrm{~g} \\ \text { Agua destilada } & 100 \mathrm{ml}\end{array}$


2.- Agar Czapek Levadura con $20 \%$ de Sucrosa(CY20S)

$\begin{array}{lr}\text { K2HPO4 } & 1 \mathrm{~g} \\ \text { Concentrado de Czapek } & 10 \mathrm{ml} \\ \text { Extracto de levadura } & 5 \mathrm{~g} \\ \text { Sucrosa } & 200 \mathrm{~g} \\ \text { Agar } & 15 \mathrm{~g} \\ \text { Agua destilada } & 1 \mathrm{~L}\end{array}$

\section{3.- Agar Czapek Levadura (CYA25, CYA37)}

$\begin{array}{lc}\mathrm{K} 2 \mathrm{HPO} 4 & 1 \mathrm{~g} \\ \text { Concentrado de Czapek } & 10 \mathrm{ml}\end{array}$

Extracto de levadura $\quad 5 \mathrm{~g}$

Sucrosa $\quad 30 \mathrm{~g}$

Agar $\quad 15 \mathrm{~g}$

Agua destilada $1 \mathrm{~L}$

\section{4.-Agar Czapec Dox (CZ)}

$\mathrm{K}_{2} \mathrm{HPO} 4$

Concentrado de Czapek $\quad 10 \mathrm{ml}$

Sucrosa $\quad 30 \mathrm{~g}$

Agar $\quad 17,5 \mathrm{~g}$

Agua destilada $1 \mathrm{~L}$

5.- Agar extracto de Malta (MEA)

Extracto de malta en polvo $20 \mathrm{~g}$

Peptona $1 \mathrm{~g}$

Glucosa $20 \mathrm{~g}$

Agar $\quad 20 \mathrm{~g}$

Agua destilada $\quad 1 \mathrm{~L}$
K) Claves anexas y su manejo.

Las claves que se detallan a continuación, pueden emplearse para determinar los más comunes aislamientos clínicos o ambientales; no son estrictamente dicotómicas y se han completado con la información más significativa y descriptiva de cada especie, para facilitar en cierta medida una mejor identificación para las personas que no poseen literatura taxonómica de las especies más comunes de Aspergillus, una situación que hemos observado en algunos laboratorios de nuestro país. La lectura de estas claves por su mayor información anexa, pueden alargar el tiempo de búsqueda de una especie, en especial si un aislamiento no corresponde plenamente con las descripciones, sin embargo, si ciertos aspectos son coincidentes, se recomienda buscar en las referencias las descripciones completas en la sección que corresponde. Las claves son siempre orientativas y es necesario hacer coincidir la descripción final con las monografías en la literatura.

Antes de usar las claves, observe bien las colonias y haga preparaciones desde 2 medios diferentes porque pueden presentarse algunas características diferentes (ej. el color del conidióforo, tamaño de las vesículas, rugosidad de los conidios, etc.). El Lactofenol puede alterar los diámetros de los conidios y a veces es preferible medir las estructuras en agua. Si un aislamiento se presenta como biseriado y monoseriado, considere como válidas las estructuras dominantes. Si el aislamiento esporula pobremente expóngalo a la luz por varios días (Aspergillus es sensitivo a la luz) o cultívelo en medios pobres (papa zanahoria (PZ), o Agar avena (OA).

L) Algunos textos a consultar : Raper \& Fennel, 1965; Klich, 2002; Samson \& Pitt, 2000; Samson et al., 2004; Samson \& Vargas $2007 \mathrm{u}$ otros trabajos citados en las referencias. 


\section{Clave general de las especies más comunes de Aspergillus en diferentes ambientes}

(Modificada de Samson et al., 2004 y Klich, 2002) Dibujos no a escala.

- Colonias blancas, negras, amarillas, café o de colores grises..........................
- Colonias en algún tono de verde, verde amarillo o azul verdoso............

2. - Cabezas conidiales de color blanco a amarillo pálido a menudo húmedas; predominantemente biseriadas, cabezas reducidas a veces presentes; diámetro de las colonias en CYA25 13-20 mm, MEA25 8-15 mm, CYA37 sin crecimiento; vesículas predominantemente más grandes que $15 \mu \mathrm{m}(10$ 40); métulas que cubren toda la superficie de la vesícula; conidios globosos a ovoides lisos 2,5-4 $\mu \mathrm{m}$. Esclerocios púrpura a negros a veces presentes. A.candidus Link (Una especie similar como A. tritici Mehrotra \& Basu, presenta colonias más amarillas, es capaz de crecer en CYA37, 7-21 mm; vesículas 5-11 mm y conidios levemente rugosos. Seguramente por su capacidad de crecer a $37^{\circ} \mathrm{C}$ se ha confundido con A.candidus en algunos tipos de micosis: ver Vargas et al., 2007c )

- Cabezas conidiales de color blanco a amarillo pálido o crema; diámetro de las colonias en CYA25 20-38 mm, MEA25 20 (o menos)-38, CYA37 y CYA20S menores de 55mm; predominantemente biseriadas; vesículas mayoritariamente menores de $15 \mu \mathrm{m}$; métulas que cubren uno o dos tercios de la superficie de la vesícula; conidios globosos, lisos a finamente rugosos 2,5-3,5 $\mu \mathrm{m}$. Células Hülle a veces presentes; cleistotecios amarillos raramente presentes (Fennellia nivea). A.niveus Blochwitz

- Cabezas conidiales amarillas, con algún tono de café o negro ... 3

3. - Cabezas conidiales café oscuras a negras; biseriadas (uniseriadas), diámetro de las colonias en CYA37 50-70 mm; conidios globosos, irregularmente rugosos a finamente rugosos, con crestas y surcos 3,5-5 $\mu \mathrm{m}$

A. niger complex van Tieghem (ver Tabla.3 para la diferencia con otras especies de la sección Nigri, Samson et al., 2007b)

- Cabezas conidiales no café oscuras a negras pero de colores oliva, amarillocafé, u otros tonos más pálidos del café

... 4

4 - Cabezas conidiales columnares, a menudo de color canela-café a café rosado; biseriados; diámetro de las colonias en CYA37 y CYA20S 60-70 $\mathrm{mm}$; métulas angostas compactadas $(2-2,5 \mu \mathrm{m})$ que cubren las $3 / 4$ de la vesícula; conidios globosos a elipsóides, lisos $2-2,5 \mu \mathrm{m}$. Células globosas hialinas (aleuroconidios) adheridos lateralmente en las hifas sumergidas usualmente presentes.

A. terreus Thom aggregates (Es un taxa con alta variabilidad genética con varias especies crípticas incluidas en los aislamientos considerados como A.terreus, Vargas et al., 2005; Lass- Flörl et al.2007 y otros estudios en preparación).

- Cabezas conidiales no columnares, de color amarillo o café. $\ldots 5$

5. - Cabezas conidiales oliva a café claro; diámetro de las colonias en CYA 25 36-43 mm, MEA25 35-46 mm, CYA37 sin crecimiento; biseriadas; estipe café; células Hülle a menudo presentes en forma de salchicha; conidios esféricos, de paredes muy rugosas 3,2-4,5 $\mu \mathrm{m}$. Reacción de Ehrlich (-). Buen crecimiento en CREA, con micelio amarillo tenue sin producción de ácido A.ustus (Bainier) Thom \& Church (A calidoustus Vargas et al., 2005, es una especie similar que se aisla en clínica y se ha confundido con A.ustus, crece bien en CYA37 entre 20-35mm; reacción de Ehrlich de color violeta, débil a moderado crecimiento en CREA con micelio hialino y sin producción de ácido. Ver la descripción de los 7 integrantes de la
Conidios y conidióforos
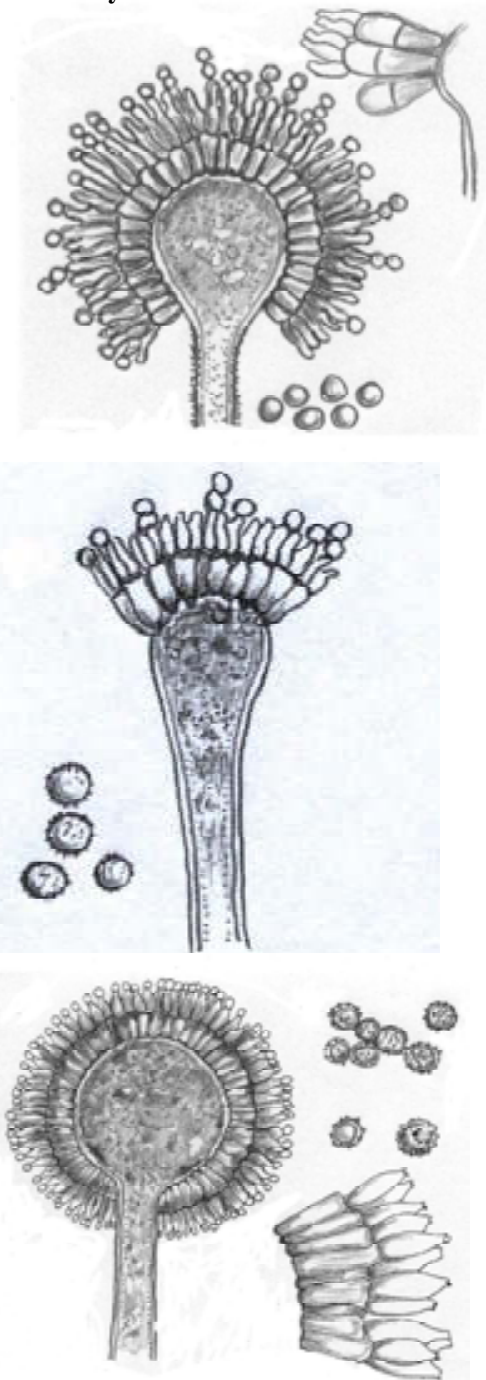

Aleuroconidio

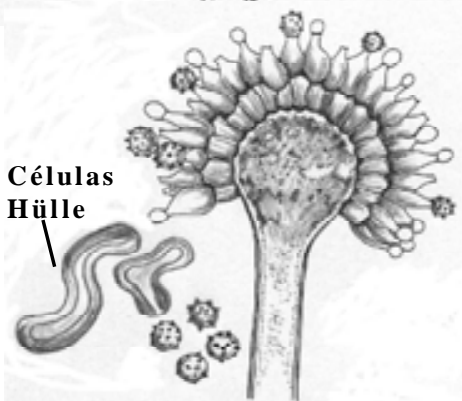


sección Usti en Houbraken et al., 2007).

- Cabezas conidiales no de color oliva, estipe hialino, amarillo o café pálido células de Hülle ausentes. ..6

6. - Cabezas conidiales en tonos amarillo, biseriadas; estipe rugoso; conidios lisos a finamente rugosos .

- Cabezas conidiales en tonos ocráceos, crema o ante; biseriadas; estipe rugoso; conidios lisos a finamente rugosos ...............8

- Cabezas conidiales en tonos amarillo-café o color cobre oliváceo uni y biseriadas; estipe rugoso o liso; conidios rugosos o con tubérculos, pared interna y externa visible o no.

7. - Cabezas conidiales en amarillo intenso; radiadas que se abren en columnas; colonias en CYA25 30-50 mm, MEA25 40-60 mm, CYA37 0-25 mm, biseriados, estipe rugoso, abundantes esclerocios amarillos a naranja, conidios globosos a elipsóides, lisos a finamente rugosos 2,5-3(-4) $\mu \mathrm{m}$

A. auricomus (Guegen) Saito

- Cabezas conidiales en amarillo pastel intenso, radiadas, que se abren en columnas; colonias en CYA25 45-60 mm, MEA25 45-56 mm, CYA37 20-30 mm, biseriados, estipe rugoso, abundantes esclerocios blancos a color ante; conidios esféricos, lisos a finamente rugosos 2,5$3(3,5) \mu \mathrm{m}$.

A. sclerotiorum Huber.

8. - Estipes largos generalmente sobre los $1000 \mu \mathrm{m}$ en MEA, rugosos, incoloros a amarillentos a café hacia el ápice; colonias en CYA25 3959 mm, MEA 44-55 mm, CYA37 0-35 mm; biseriados, métulas que cubren la vesícula entera; conidios globosos a ampliamente elipsóides lisos a finamente rugosos 2,5-3 (-4,5) $\mu \mathrm{m}$. Esclerocios cuando están presentes, rosados a púrpura.

A.ochraceus K. Wil.

- Estipes más cortos, generalmente menores de $800 \mu \mathrm{m}$ en MEA, rugosos, incoloros a amarillentos a café hacia el ápice; colonias en CYA25 30$50 \mathrm{~mm}$, MEA 33-60 mm, CYA37 20-37mm; biseriados, métulas que cubren casi la vesícula entera; conidios globosos a ampliamente elipsóides lisos a finamente rugosos 3-3,5 (4) $\mu \mathrm{m}$. Esclerocios esféricos a elongados, de color amarillo, ante a colores café..

A.melleus Yukawa

9. - Cabezas conidiales radiadas que se separan en columnas, de color bronce a café con la edad; colonias en CYA25 55-70 mm, MEA 65-70 mm, CYA37 40-70 mm; uni o biseriadas; estipe largo 600-1500 o más x 12- $20 \mu \mathrm{m}$, incoloro, rugoso; métulas o fiálides que cubren la vesícula entera; conidios en cadenas largas que se mantienen unidas, globosos, conspicuamente ornamentados y rugosos con pared externa e interna visible, 5,5- $8 \mu \mathrm{m}$

A tamarii Kita

(A.caelatus Horn,1977, tiene un color amarillo más intenso en el reverso en CYA25 que A.tamarii y estipes más cortos en MEA (menores de $1000 \mu \mathrm{m})$. A.pseudotamarii Ito, produce aflatoxinas y en $\mathrm{CZ} 37^{\circ} \mathrm{C}$ el diámetro de las colonias son menores de $33 \mathrm{~mm}$, ver Ito et al., 2001).

- Cabezas conidiales radiadas que se separan en columnas, de color amarillo grisáceo a oliva café, biseriadas; diámetro de las colonias en CYA25 25-35 mm, MEA 25-35(40) mm, nocrece en CYA37; estipe largo generalmente sobre los $1000 \mu \mathrm{m}$ (hasta 3000) x 12- 25 $\mu \mathrm{m}$, incoloro, de pared lisa o a veces ligeramente rugosa hacia el ápice. Conidios

\section{Conidios y conidióforos}
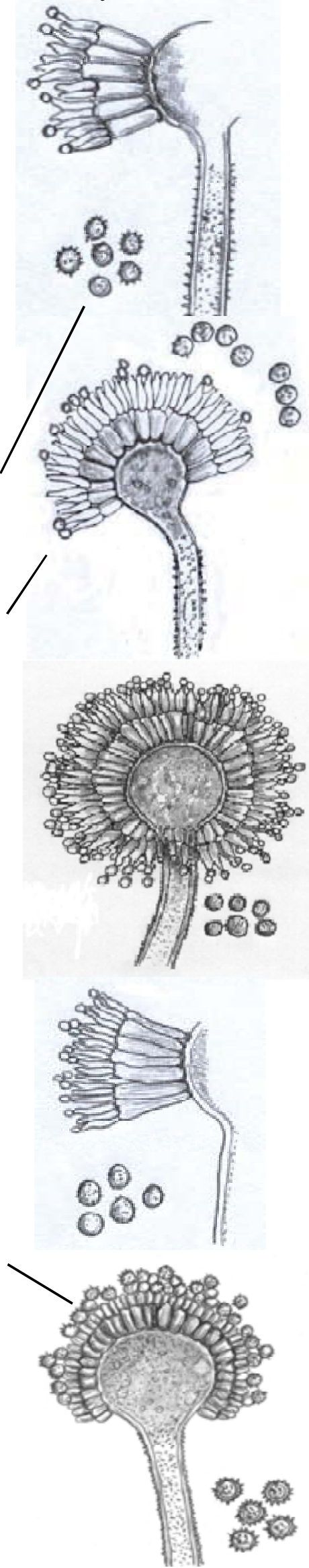
globosos, subglobosos a elipsóides, lisos a rugosos, con crestas, 4$5(-6) \mu \mathrm{m}$, sin una doble pared visible.

A.wentii Wehmer

10. - Colonias verde oscuro,crecimiento en CYA25 40-60 mm, MEA 53-65 mm,CYA37, de $50 \mathrm{~mm}$ o más; conidióforos cortos, café, biseriados con métulas que cubren la mitad superior de la vesícula; conidios esféricos, lisos a finamente rugosos 3-4 $\mu \mathrm{m}$. Cleistotecios de $\mathbf{E m e}$ ricella a menudo presentes, globosos, de paredes de color rojo oscuras al madurar, recubiertas de células de Hülle de color amarillo a ante. Ascosporas (maduran a las 2 semanas), redondas a lenticulares en vista lateral, rojo púrpura, lisas, 4-6 x 3-4 $\mu \mathrm{m}$ con 2 rebordes finos longitudinales de cerca de $1 \mu \mathrm{m}$ en vista lateral Emericella nidulans

(Eidam) Vuill., anamorfo A. nidulans (Eidam) G.Winter

(La especie relacionada Emericella quadrilineata se diferencia sólo por tener ascosporas lisas con 4 rebordes longitudinales, mientras $\boldsymbol{E}$. rugulosa, presenta ascosporas ampliamete lenticulares 5-6,5 x 3-4,5 $\mu \mathrm{m}$, de paredes generalmente rugosas, pero a veces lisas en algunos aislamientos, con 2 rebordes finos longitudinales y crece más lentamente en CYA25 10-17 (33)mm y MEA25 12-20 (-42) mm,que las 2 anteriores.Ver Klich, 2002).

- Colonias verde oscuro a gris verdoso amarillento, cleistotecios ausentes o presentes (excluyendo Emericella) .. 11

11. - Colonias restringidas en CYA y MEA25 entre 15-25 mm, CYA20S 1430 y CYA37 0-17mm, cleistotecios presentes o ausentes...................12 - Colonias muy restringidas en CYA y MEA25 $(<15 \mathrm{~mm} \mathrm{o}<$ de $10 \mathrm{~mm}$ en 7 días), que crecen más rápido en CYA20S a los 7-14 días, no crecen $\underline{\mathbf{a} 37^{\circ} \mathrm{C}}$; cleistotecios ausentes ..

. .13

- Colonias no restringidas, mayores de $30 \mathrm{~mm}$ en CYA y MEA, cleistotecios ausentes 15

- Colonias de color verde oscuro con tonos amarillentos variables, cabezas biseriadas, radiadas, estipe incoloro, amarillento a café claro; métulas que cubren la mitad superior hasta los $2 / 3$ de la vesícula; conidios globosos a subglobosos, finamente a conspicuamente rugosos 2-3,5 $(4,5) \mu \mathrm{m}$, células Hülle raramente presentes, cleistotecios ausentes.

.A. versicolor (Vuill.) Tiraboschi

- Colonias de color gris verdoso a verde oscuro, de crecimiento más rápido, generalmente $>$ de $15 \mathrm{~mm}$ en CYA y MEA25, gris verdosas a verde oscuro, cabezas conidiales uniseriadas estrictas, cleistotecios amarillos presentes, con ascos evanescentes de 8 ascosporas; células de Hülle ausentes .

13. - Colonias en colores pálidos, gris verdosas, cabezas radiadas al inicio, después variables; crecimiento en CYA y MEA25 raramente exceden los $8 \mathrm{~mm}$, estipe incoloro, liso, vesículas uniseriadas subglobosas a espatuladas 9-25 $\mu \mathrm{m}$; conidios semiesféricos a elipsoides, finamente a francamente rugosos, los conidios elipsoides miden 3-5,5(6) x 3-4 $\mu \mathrm{m}$, los esféricos 3-5 $\mu \mathrm{m}$

A. penicillioides Speg.

- Colonias grises a verde oscuro; cabezas conidiales columnares; crecimiento en CYA y MEA 25, raramente exceden los 13mm; estipe liso o finamente rugoso, incoloro con vesículas uniseriadas; fiálides que cubren solo la parte superior de la vesícula, conidios cilíndricos cuando nacen, posteriormente elipsoidales a piriformes, generalmente rugosos $4-7$ x $3-4(-5,5) \mu \mathrm{m}$.

A. restrictus G.Smith (A. penicillioides y A. restrictus se aislan y cultivan mejor en medios de baja actividad de agua (DG18, CYA20S, MA20-40G), permitiendo una mejor identificación).
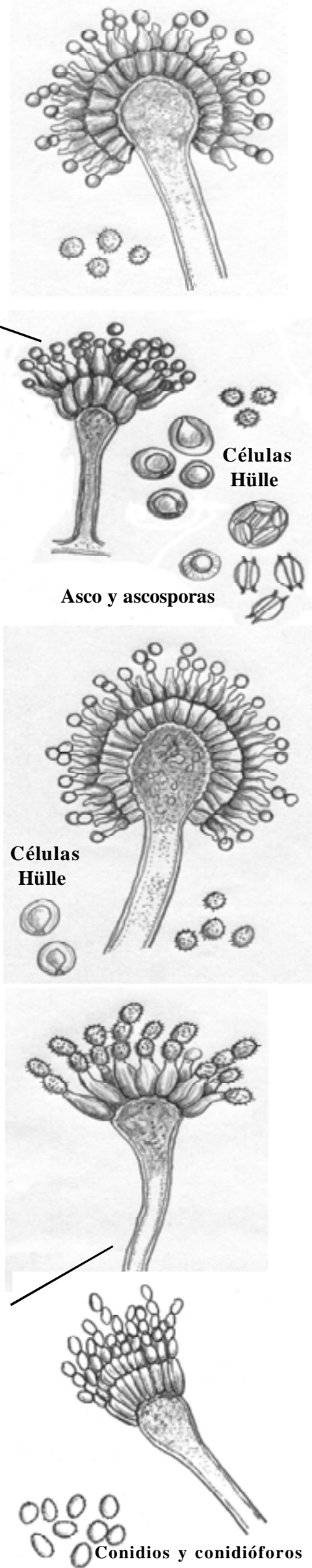
14. - Cleistotecios amarillos de Eurotium con una sola capa de células angulares parenquimatosas, rodeados de hifas, especialmente en cultivos viejos y en CYA20S con diámetros de 30-45 (60) mm (como mínimo el doble que en CYA y MEA25), no crece a $37^{\circ} \mathrm{C}$; ascosporas que maduran en 14 días, lenticulares, lisas, a menudo con un surco central, 5-6,5 x 3-5 $\mu \mathrm{m}$. Cabezas conidiales radiadas, estipe incoloro, de pared lisa o rugosa, fiálides que cubren las 3/4 partes de la vesícula; conidios espinosos, variables en tamaño, esféricos, elipsoides, o apiculados, finamente rugosos a espinosos, 5-8 (11) x 5-7 $\mu \mathrm{m}$ ................Eurotium herbariorum Link,(anamorfo A.glaucus Link) (E. repens y $\boldsymbol{E}$. rubrum son 2 especies estrechamente relacionadas con $\boldsymbol{E}$. herbariorum. La primera difiere por la formación de ascosporas sin surcos distintivos, mientras $\boldsymbol{E}$. rubrum tiene surcos más notorios y sus hifas adquieren colores ladrillo a rojo con la edad. Domsch et al.,1980, consideran a estas 2 especies como sinónimos de $\boldsymbol{E}$. herbariorum).

- Cleistotecios amarillos de Eurotium con una sola capa de células angulares parenquimatosas, rodeados de hifas, especialmente en cultivos viejos en CYA20S, con diámetros de 34-60 mm (como mínimo el doble que en CYA y MEA25); ascosporas incoloras, de paredes rugosas que maduran en 14 y 21 días, lenticulares, con un surco central y 2 rebordes longitudinales, 4,5-6, x 3,5-4 $\mu \mathrm{m}$. Cabezas conidiales radiadas a columnares, estipe incoloro a levemente café, liso, fiálides que cubren los 2/3 de la vesícula; conidios, esféricos a subglobosos, finamente rugosos a espinosos 4-5 (-7) $\mu \mathrm{m}$....Eurotium amstelodami Mangin (anamorfo A. vitis Novobr.)

- Cleistotecios amarillos de Eurotium con una sola capa de células angulares parenquimatosas, rodeados de hifas, especialmente en cultivos viejos en CYA20S, con diámetros de 45-68 mm (como mínimo el doble que en CYA y MEA25); ascosporas incoloras, lisas, que maduran en 7-14 días, lenticulares, con 2 rebordes longitudinales salientes en forma de polea, 4,5-5,5 (7) x 3,5-4 $\mu \mathrm{m}$. Cabezas conidiales radiadas, estipe incoloro a cafesoso, liso; fiálides que cubren los $2 / 3$ de la vesícula; conidios, variables en tamaño, desde globosos, ovoides a piriformes, finamente rugosos a espinosos, 4-5 (-7) x 3-4 $\mu \mathrm{m}$ .......................Eurotium chevalieri L.Mangin (anamorfo: A. chevalieri Ibid.)

15. - Cabezas conidiales amarillo-verde a amarillo o verde oscuro......... 16

- Cabezas conidiales azules a azul verdoso oscuro a grisáceo. 20

16. - Cabezas conidiales uni o biseradas, conidios lisos a finamente rugosos

- Cabeza conidiales predominantemente uniseriadas, conidios conspicuamente rugosos

17. - Cabezas conidiales radiadas a columnares; que permanecen de color oliva verde a verde amarillento en el tiempo en CYA25; diámetro de las colonias en todos los medios y temperaturas mayores de $50 \mathrm{~mm}$; estipe rugoso, incoloro, a veces en tonos café pálidos; vesículas biseriadas generalmente en un $20 \%$, pero variable; en MEA a veces, enteramente uniseriadas; métulas/fiálides que cubren $\operatorname{los} 3 / 4$ de la vesícula; conidios globosos a elipsoides 3- 6 (-8) $\mu \mathrm{m}$. Esclerocios generalmente presentes, redondos de colores café, violeta a negros

A. flavus Link (Las poblaciones de $\boldsymbol{A}$ flavus, presentan a menudo aislamientos con 2 tipos de tamaño de esclerocios, unas llamadas cepas L superiores a $400 \mu \mathrm{m}$ y otras llamadas cepas $\mathbf{S}$ inferiores a los $400 \mu \mathrm{m}$, estas últimas producen

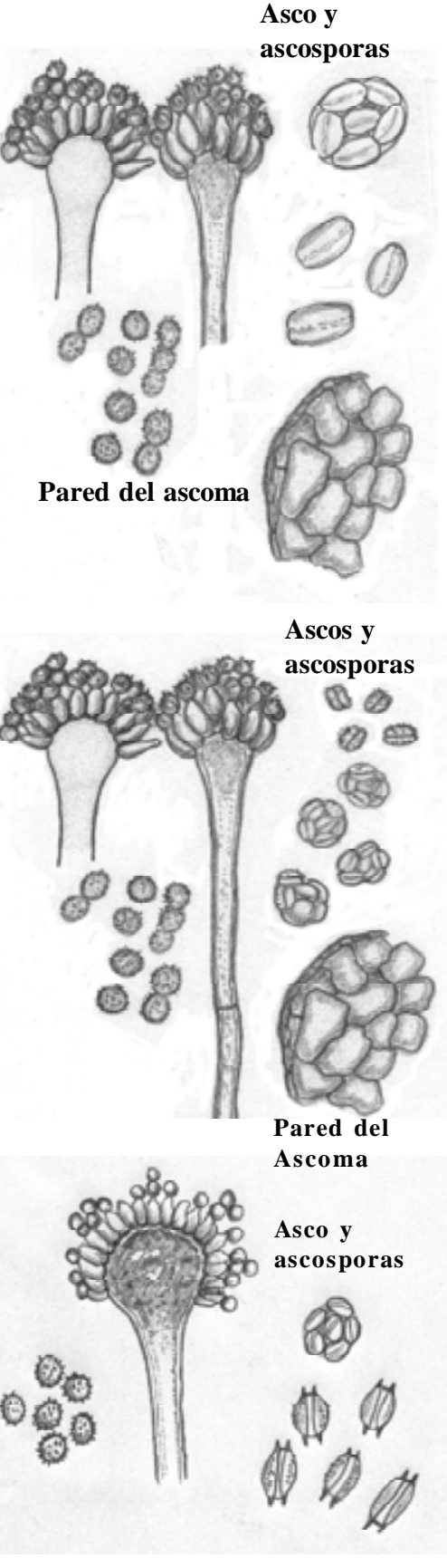

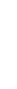

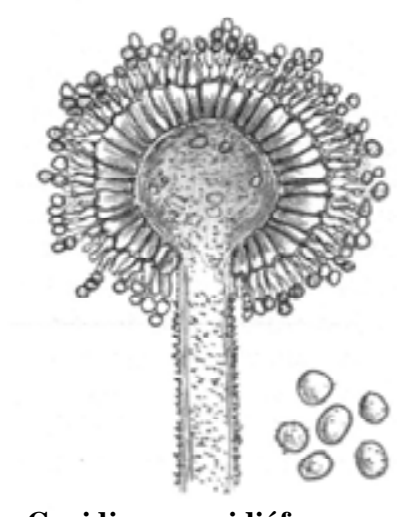

Conidios y conidióforos 
gran cantidad de aflatoxinas B. Las especies relacionadas como A.nomius, se distingue de A.flavus por producir aflatoxinas $\mathrm{B}, \mathrm{G}$ y producir esclerocios alargados, mientras la rara especie A.bombycis crece lentamente en CYA37 (0-37 mm en 7 días) y presenta un estipe liso).

- Cabezas conidiales radiadas a laxamente columnares, de color gris amarillento que se tornan oliva café con el tiempo en CYA25; características de crecimiento similares a A.flavus, estipe rugoso, incoloro, vesículas predominantemente uniseriadas, pero a veces lo contrario (biseriadas); métulas/fiálides que cubren la mitad o más de la vesícula; conidios globosos a elipsoides 4-8,5 (-10) $\mu \mathrm{m}$....

A.oryzae (Ahlburg) Cohn.

(Se considera actualmente a A. oryzae no como una especie diferente, sino un ecotipo diferente de A.flavus).

18. - Conidios globosos, usualmente entre 3,5-6 $\mu \mathrm{m}$ en diámetro (rugosos); colonias que mantienen un color amarillo verdoso oscuro o tonalidades verdes en el tiempo en CIA25; cabezas conidiales usualmente radiadas; estipe incoloro, finamente a muy rugoso.

A.parasiticus Speare

- Conidios globosos, usualmente 5-8 $\mu \mathrm{m}$ en diámetro, colonias usualmente de color bronce a café en el tiempo en CYA 25. 19

19. - Cabezas conidiales radiadas a laxamente columnares, de color oliva a café en CYA25, predominantemente uniseriadas; estipe incoloro liso a rugoso; fiálides/métulas que cubren la mitad de la vesícula; conidios de paredes finas, rugosas pero sin tubérculos sobresalientes, de colores oscuros 5,5-7 $\mu \mathrm{m}$..........A. sojae Sakaguchi \& Yamada ex Murak

(Esta especie se aísla prácticamente sólo de las fermentaciones del koji).

- Cabezas conidiales radiadas que se abren en cortas columnas de color café verdoso intenso o amarillo café en CYA25, uni y biseriadas, con estipe rugoso incoloro; fiálides/métulas que cubren usualmente la vesícula entera; conidios rugosos, de paredes gruesas, con las 2 paredes visibles, ornamentados con tubérculos de colores oscuros, 5,5-8 $\mu \mathrm{m}$

A.tamarii Kita

20. - Colonias de crecimiento reducido en CYA37 (2-10) mm; cabezas conidiales radiadas predominantemente biseriadas, de un color azul verdoso, a turquesa; en CYA25 semejante a colonias de Penicillium; colonias menores de $35 \mathrm{~mm}$ en CYA25 y CYA20S; estipe incoloro a café pálido (menores de $500 \mu \mathrm{m}$ de largo); en el micelio aéreo se presentan cabezas conidiales pequeñas, semejando penicillios; conidios esféricos rugosos a espinosos, 3-4 $(4,5) \mu \mathrm{m}$.

A. sydowii (Bain. \& Sart.) Tom \& Church

- Colonias de regular crecimiento en CYA37, menores de $30 \mathrm{~mm}$; cabezas conidiales radiadas a clavadas, que se abren en columnas con la edad; estrictamente monoseriadas; colonias en CYA25 y CYA20S mayores de $35 \mathrm{~mm}$; estipes largos y anchos (con promedios mayores de 1000 x 10-30 $\mu \mathrm{m}$ ), de paredes lisas, incoloros a levemente café cerca del ápice; vesículas típicamente espatuladas con áreas fértiles de hasta $250 \mu \mathrm{m}$ de largo; conidios lisos, mayoritariamente elipsoidales, a veces apiculados a cilíndricos, 3-6 x 2,5-4 $\mu \mathrm{m}$.......A.clavatus Desm.

(A.giganteus Wemer, tiene mayor crecimiento en MEA25 (43-65 mm), estipe de 2 tipos, 2-3 (-4) mm o varios cent. Vesículas más anchas, de 2 tipos; en conidióforos cortos 30-50 $\mu \mathrm{m}$ y en largos de 120-180 $\mu \mathrm{m}$. Para una revisión taxonómica de la sección Clavati ver Vargas et al, 2007b)

- Colonias de gran crecimiento en CYA37, mayores de $55 \mathrm{~mm}$ de diámetro.

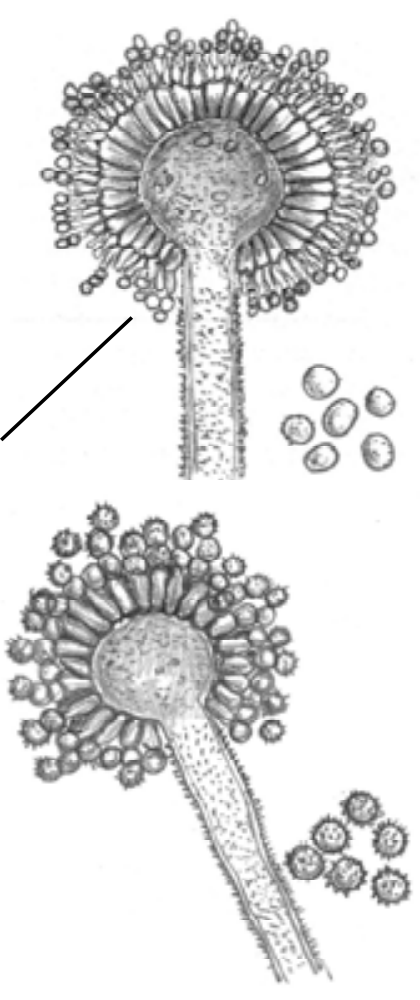

\section{Sin dibujo}

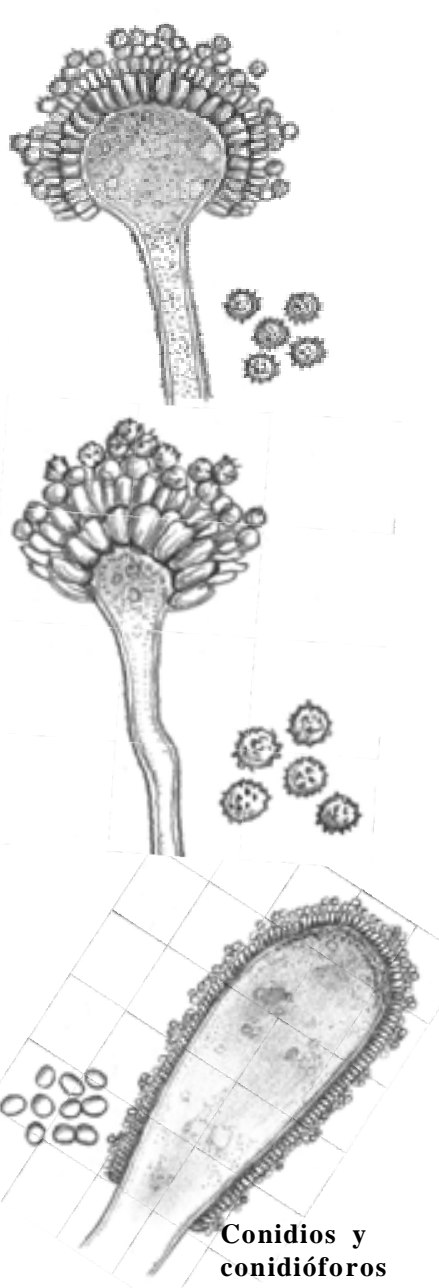


21. - Cleistotecios presentes, tomentosos, hialinos a crema, con ascosporas hialinas, lenticulares a esféricas con borde sobresaliente 5-8 x 4-5 $\mu \mathrm{m}$. Anamorfo semejante a A.fumigatus presente, con cabezas columnares, vesículas piriformes, monoseriadas; conidios esféricos a elipsoidales, lisos a finamente rugosos, 2,5-3,5 x 2-3 $\mu \mathrm{m}$ Neosartorya fischeri* (Wehmer) Malloch \& Cain (anamorfo A . fischerianus Samson \& W.Gams)

(Ver diferencias con otras especies del género en Clave $\mathbf{N}^{\mathbf{0}}$ 2)

- Cleistotecios ausentes; cabezas conidiales columnares, con vesículas ampliamente clavadas, estipe incoloro a gris cerca del ápice; vesículas uniseriadas con fiálides que cubren la mitad o la tercera parte de la Ascospora vesícula, dispuestas en forma paralela con el eje del estipe; conidios al SEM globosos a ampliamente elipsoides, lisos a finamente rugosos o espinosos 2-3 $\mu \mathrm{m}$ en diámetro

A. fumigatus Fresen.

(Es una de las especies de gran distribución en una amplia variedad de substratos y ambientes; es el más común oportunista patógeno en humanos y otros mamíferos, ver clave $\mathbf{N}^{\circ} \mathbf{2}$ para diferenciarla de otras especies semejantes del subgénero Fumigati).

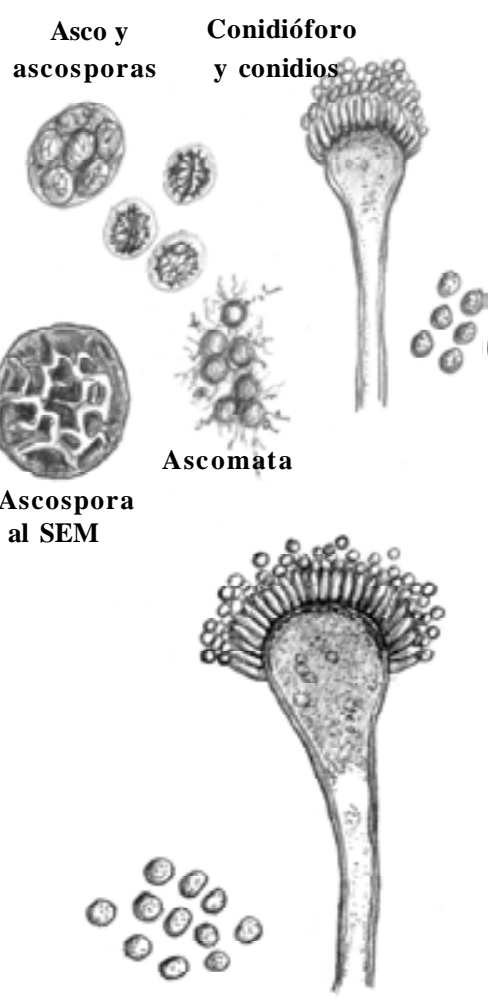

\section{Clave $\mathrm{N}^{\circ} 2$ morfofisiológica (tentativa) para la determinación de las especies del subgé- nero Fumigati con y sin producción de cleistotecios en cultivos (7 días de incubación).}

(Para una descripción completa (polifásica) de las especies de importancia ya sea ecológica como clínica, debe consultarse Hong et al., 2005; Balajee et al., 2007 y Samson et al., 2007)

1. - Ausencia de cleistotecios en cultivos . .2

- Presencia de cleistotecios en cultivos 12

2. - Conidios en MEA verde grises a azul verdosos, dispuestos en columnas. 3 - Conidios en MEA rosados a púrpura rojo en masa, dispuestos en columnas cortas, crecimiento en CYA37 16-19 $\mu \mathrm{m}$ (máximo $42^{\circ} \mathrm{C}$ ); vesículas pequeñas en forma de pera y dispuestas en ángulo recto (al igual que A.viridinutans y A.duricaulis) $10-18 \mu \mathrm{m}$ de ancho, conidios globosos, espinulosos 2,8-3,5 $\mu \mathrm{m}$ Aspergillus brevipes Smith (Se ha aislado en Australia y se asemeja a A. duricaulis)

3. - Cabezas conidiales predominantemente clavadas, colonias en $\mathrm{CYA} 37^{\circ} \mathrm{C}$ menores que $30 \mathrm{~mm}$..... Vea Aspergillus clavatus Desm.(clave anterior)

- Cabezas conidiales predominantemente piriformes, espatuladas, subglobosas a globosas; colonias en $\mathrm{CYA} 37^{\circ} \mathrm{C}$ mayores o menores de $55 \mathrm{~mm}$

4. - Colonias que crecen a $50^{\circ} \mathrm{C}$ 5

- Colonias que no crecen a $50^{\circ} \mathrm{C}$

5. - Colonias en CYA37 $60-75 \mathrm{~mm}$; crecimiento a $50^{\circ} \mathrm{C}$ pero no a $10^{\circ} \mathrm{C}$; cabeza conidial columnar, estipe 50-350 x 3,5-10 $\mu \mathrm{m}$ (generalmente entre 6-10 $\mu \mathrm{m}$ de ancho); vesícula piriforme a subclavada $10-26 \mu \mathrm{m}$; conidios 2-3,5 $\mu \mathrm{m}$, globosos a elipsoides, lisos a finamente rugosos (Es la especie más patogénica en humanos) .....Aspergillus fumigatus Fresenius

(Especies similares: A. fumigatiaffinis, A. fumisinnematus, A. lentulus, A. novofumigatus, $A$. viridinutans).

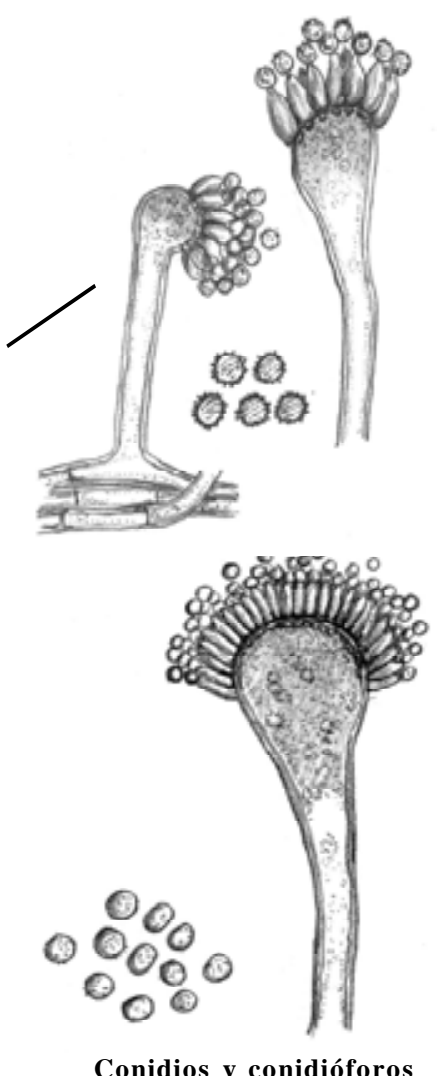

Conidios y conidióforos 
- Colonias en CYA37 50-70 $\mu$ m o más; crecimiento a $50^{\circ} \mathrm{C}$ y a $10^{\circ} \mathrm{C}$; cabeza conidial columnar corta, estipe $80-100 \times 4-7 \mu \mathrm{m}$, vesícula globosa o en forma de matraz, 15-25 $\mu$ m de ancho; fiálides que cubren $10 \mathrm{~s} 3 / 4$ de la vesícula, conidios 2,5-3 $\mu \mathrm{m}$ subglobosos, lisos (aislado en Corea del Sur)

Aspergillus turcosus Hong, Frisvald \& Samson

6. - Colonias que crecen hasta $45^{\circ} \mathrm{C}$, crecimiento a $10^{\circ} \mathrm{C}$ negativo o positivo

- Colonias que crecen hasta $\operatorname{los} 42^{\circ} \mathrm{C}$

7. - Crecimiento negativo a $10^{\circ} \mathrm{C}$; presencia de sinnema en el tiempo e hifas funiculosas aéreas; crecimiento en CYA $3757-61 \mathrm{~mm}$; estipe hasta 210 x 6$8,5(-10) \mu \mathrm{m}$; vesícula hemiesférica 16-20 (-25) $\mu \mathrm{m}$; conidios ampliamente elipsoidales, verruculosos, 2,8-2,3 x 2,4-2,8 $\mu \mathrm{m}$ (patogénico en humanos) Aspergillus fumisynnematus Horie et al. (Distribución: Brasil, Venezuela, España. Especies similares: A. fumigatiaffinis, A. fumigatus, A. lentulus, A. novofumigatus)

- Crecimiento positivo a $10^{\circ} \mathrm{C}$, ausencia de sinnema e hifas funiculosas en el tiempo ...8

8. - Crecimiento lento en CREA (ver Tabla $3^{*}$ ), sin producción de ácido ......... 9

- Crecimiento lento en CREA con producción de ácido (las demás especies integrantes de la clave no producen ácido en CREA, salvo A.fumigatus, que a veces puede presentar una débil producción); crecimiento positivo a $10^{\circ} \mathrm{C}$; crecimiento en CYA37 65-70 mm; estipe, 6-8 $\mu \mathrm{m}$ diam.; vesículas globosas a subglobosas 18-24 $\mu \mathrm{m}$; conidios 2-3 $\mu \mathrm{m}$ globosos a subglobosos, lisos .......... Aspergillus fumigatiaffinis Hong, Frisval \& Samson

(Distribución: USA, España. Especies similares: A. fumigatus, A. lentulus, A. novofumigatus).

9. - Crecimiento positivo a $10^{\circ} \mathrm{C}$; conidiación pobre pero abundante en algunos aislamientos; crecimiento en CYA37 54-70 mm, estipe 20-500 x 4-6(-7) $\mu \mathrm{m}$, a veces sinuoso y constreñido; vesícula $10-25 \mu \mathrm{m}$, globosa a piriforme, usualmente subglobosa; conidios globosos a ampliamente elipsoidales, lisos a finamente rugosos 2-3,2 $\mu \mathrm{m}$ (patogénico en humanos).

Aspergillus lentulus Balajee \& Marr

(Distribución cosmopolita. Especies similares: A. fumigatiaffinis, A.fumigatus, A. fumisinnematus, A. novofumigatus, A. viridinutans).

- Crecimiento positivo a $10^{\circ} \mathrm{C}$; crecimiento en CYA37 49-52 mm; estipe 50500 x 4-7 mm, vesícula subglobosa a forma de matraz, relativamente ancha (13) 15-30 $\mu \mathrm{m}$, Conidios 2,5-3 $\mu \mathrm{m}$, elipsoidales, lisos.

Aspergillus novofumigatus Hong, Frisvald \& Samson

(Se ha aislado solamente en las islas Galápagos y en Ecuador. Especies similares: A. fumigatiaffinis, A. fumigatus, A. fumisinnematus, A. lentulus )

10. - Crecimiento en MEA 25, menor de $30 \mathrm{~mm}$ en 7 días .11

- Crecimiento en MEA25 mayor que $30 \mathrm{~mm}$ en 14 días (60-70 mm); estipe corto 50-30 x 1,2-2,2 $\mu \mathrm{m}$; vesículas pequeñas 4-8,5 $\mu \mathrm{m}$; irregularmente globosas; conidios globosos, finamente rugosos 2,5-3,5 $\mu \mathrm{m}$ (Características distintivas: crecimiento lento, reverso negruzco en CYA y fiálides en racimo en un lado de la vesícula)..... Aspergillus unilateralis Thrower

(Distribución: Australia)
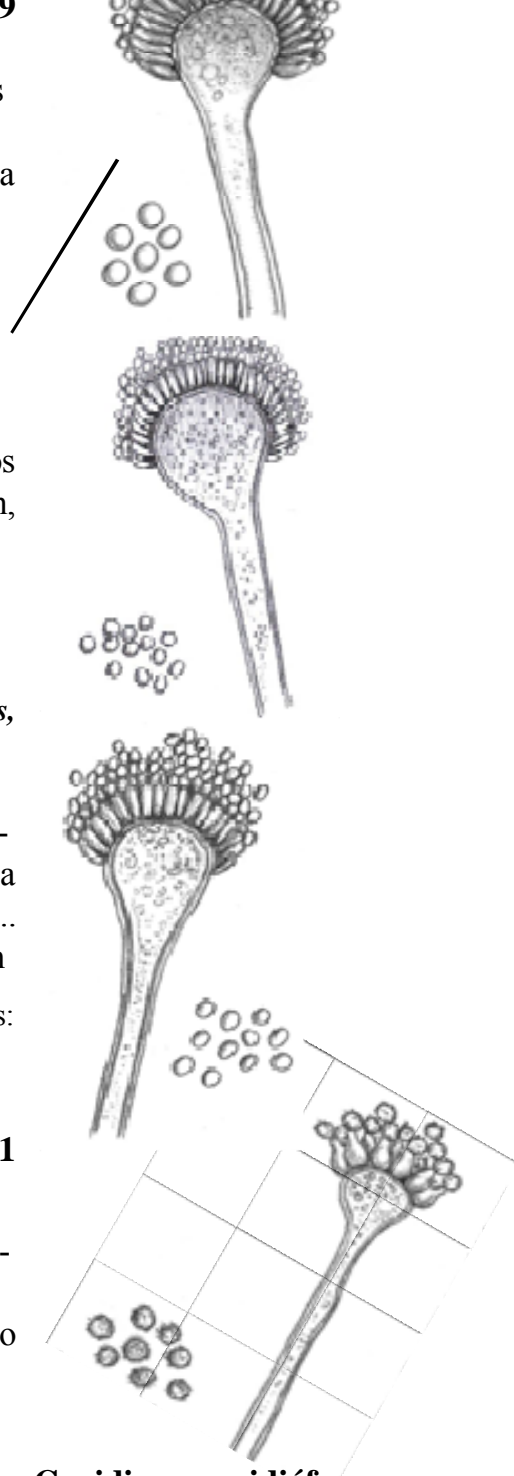

Conidios y conidióforos 
11. - Crecimiento en MEA25 11-14 mm; estipe 20-35x 3,3-4,4 $\mu$ m; vesícula subglobosa a forma de matraz, 7,5-12, que se desvía en ángulo recto; conidios globosos, finamente rugosos, 2-2,6 $\mu$ m....Aspergillus viridinutans Ducker $\&$ Thrower (patógeno en humanos).

(Distribución: Australia, Sri Lanka, Zambia, Rusia, Chile)

- Crecimiento en MEA25 20-22 mm; estipe 5-50 x 3,5-5,5 $\mu \mathrm{m}$; vesículas en forma de matraz 7-14 $\mu \mathrm{m}$; conidios $(2,8) 3-3,2(-3,3) \mu \mathrm{m}$, globosos, equinulados. Aspergillus duricaulis Raper \& Fennel

(Distribución: Argentina. Especie similar: A.brevipes)

12. - Colonias en CYA25 mayores de $40 \mathrm{~mm}$ .13

- Colonias en CYA25 menores de $40 \mathrm{~mm}$

13. - Ascosporas lenticulares, con un patrón reticulado de crestas irregulares 7-8 × 3-4 $\mu \mathrm{m}$; conidios subglobosos a elipsoides, finamente rugosos, 2 2,5 o hasta $3 \mu \mathrm{m}$, cuando globosos. Colonias en CYA25 45-68 mm ........... ............... Neosartorya fischeri (Wehmer) Malloch \& Cain (anamorf Aspergillus fischeranus Samson \& W.Gams)

(Especie cosmopolita, patógena en el hombre y otros mamíferos. Especie similaı N.tatenoi)

(Leyenda: a. Asco y ascosporas, b. Ascospora vistas al SEM, c.Ascomata en cultivo, d. Conidióforo y conidios)

- Ascosporas lenticulares espinosas, verrucosas o tuberculadas

14. - Colonias en CYA25 60-70 mm. Ascosporas sin un patrón reticulado de crestas irregulares, la ornamentación superficial corresponde a colgajos triangulares de tejido; conidios globosos a subglobosos lisos, 3-4 $\mu \mathrm{m}$

.Neosartorya pseudofischeri Peterson (anamorfo Aspergillus thermomutatus (Paden) Peterson. (Especie aparentemente cosmopolita, patógena en humanos)

(Leyenda: a. Asco y ascosporas, b. Ascospora vista al SEM, c. Conidióforo y conidios)

- Colonias en CYA25 41-70 mm. Ascosporas lenticulares, 4,5 $\mu \mathrm{m}$, espinosas, con espinas de varios tamaños $(<0,5$ hasta $7 \mu \mathrm{m})$ o con proyecciones en la parte convexa, con 2 crestas ecuatoriales separadas y anchas; conidios globosos, finamente rugosos, 2-2,5 $\mu \mathrm{m}$....... Neosartorya spinosa (Raper \& Fennell) Kozakiewicz (anamorfo: Aspergillus spinosus Kozakiewicz)

(Aparentemente cosmopolita. Leyenda: a. Asco y ascosporas, b.Ascospora vista al SEM, c. Conidióforo y conidios)

15. - Colonias en CYA25 12-14 mm, en CYA37 27-30 mm. Ascosporas lenticulares, finamente reticuladas $4,5-5 \mu \mathrm{m}$, con 2 crestas ecuatoriales poco separadas; conidios pequeños, globosos a subglobosos 2-2,5 $\mu \mathrm{m}$, lisos a finamente rugosos Neosartorya hiratsukae Tsubouchi \& Horié (anamorfo: A. hiratsukae Tsubouchi \& Horié).(Distribución, Japón, Brasil,Corea del Sur. Especies similares: $N$. fischeri, $N$. tatenoi )

(Leyenda: a. Asco y ascosporas, b. Ascospora vista al SEM, c. Conidióforo y conidios)
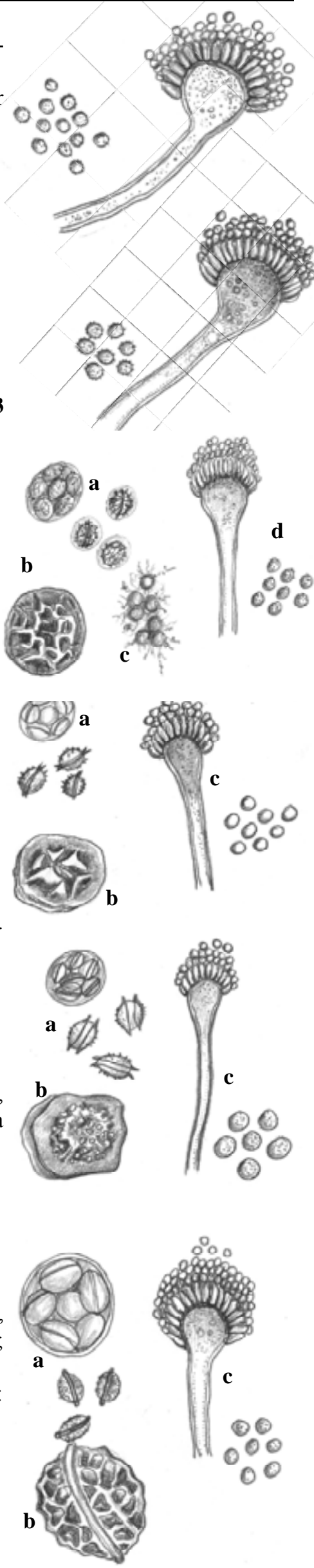
- Colonias en CYA25 33-36 mm, en CYA37 61-65 mm. Ascosporas lenticulares de superficie tuberculada, con 2 crestas ecuatoriales a menudo irregulares 5-5,5 x 4-5 $\mu \mathrm{m}$; conidios subglobosos a ampliamente elipsoides, lisos 2,6$3,2 \times 2,4-2,6 \mu \mathrm{m}$ Neosartorya udagawae Horie, Miyaji \& Nishim. (anamorfo: Aspergillus udagawae Horie, Miyaji \& Nishim.)

(Distribución: Brasil USA, España, Japón.Especies similares: N. aureolata,

\section{A. viridinutans)}

(Las especies de Neosartorya son más de 20, sólo se presentan en las claves las más comunes en distribución y las 5 encontradas como patógenas oportunistas en el hombre. Para la descripción de todas las especies ver Samson et al., 2007)

(Leyenda: a. Asco y ascosporas, b. Ascospora vista al SEM,

$$
\text { c. Conidióforo y conidios) }
$$

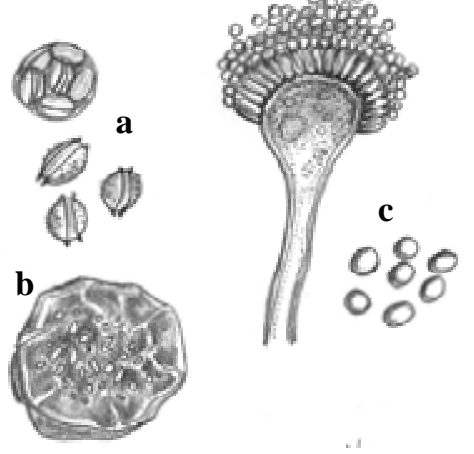

Tabla 3. Algunas características morfofisiológicas de utilidad para las diferentes especies de Aspergillus de la sección Nigri. Modificado de Samson et al., 2007. (Los datos de secuencias del gene calmodulina permiten distinguir todas las especies de la sección)

\begin{tabular}{|c|c|c|c|c|c|}
\hline $\begin{array}{l}\text { Especies } \\
\text { Uniseriadas }\end{array}$ & $\begin{array}{c}\text { Conidios } \\
\mu \mathrm{m}\end{array}$ & Superficie & $\begin{array}{c}\text { Vesícula } \\
\mu \mathrm{m}\end{array}$ & $\begin{array}{l}\text { Temp. } \\
\text { max }^{\circ} \mathbf{C}\end{array}$ & $\begin{array}{l}\text { CREA* } \\
\text { prod.ac. } \\
\text { crecimiento* }\end{array}$ \\
\hline
\end{tabular}

$\begin{array}{llllll}\text { A. aculeatinus } & 2,5-4,5 & \text { finam.rugosa } & 45-80 & 36 & 3-3 \\ \text { A. aculeatus } & 3,5-5 & \text { finam.rugosa } & 60-80 & 36 & 2-3 \\ \text { A. japonicus } & 3,5-5 & \text { finam. rugosa } & 20-35 & 36 & 3-1 \\ \text { A. uvarum } & 3-4 & \text { espinosos } & 20-30 & 36 & 1-1\end{array}$

\section{Especies}

\section{Biseriadas}

\begin{tabular}{|c|c|c|c|c|c|c|}
\hline A. brasiliensis & $3,5-4,5$ & espinosos & $30-45$ & 40 & $4-4$ & ++ amarillo \\
\hline A. carbonarius & $7-9$ & espinosos & $40-80$ & 36 & $3-3$ & - \\
\hline A. costaricarensis & $3,1-4,5$ & finam. rugosa & $40-90$ & 40 & $5-5$ & ++++ azul \\
\hline A. ellipticus & $3,5-5-5$ & lisos-finam.rug. & 75-100 & 30 & $2-2$ & - \\
\hline A. foetidus & $3,5-4,5$ & lisos-finam.rug. & $50-80$ & 40 & $4-4$ & ++ amarillo \\
\hline A. heteromorphus & $3,5-5$ & espinosos & $15-30$ & 33 & $2-2$ & $\begin{array}{l}++++ \text { amarillo } \\
\text { con halo púrpura }\end{array}$ \\
\hline A. homomorphus & $5-7$ & espinosos & $50-65$ & 36 & $2-2$ & idem anterior \\
\hline A. ibericus & $5-7$ & finam.espinosa & $50-60$ & 40 & $3-3$ & ++ amarillo \\
\hline A. lacticoffeatus & $3,4-4,1$ & lisos & $40-65$ & 40 & $3-1$ & - \\
\hline A. niger & $3,5-5$ & finam.rugosa & $45-80$ & 40 & $5-5$ & ++ amarillo \\
\hline A. piperis & $2,8-3,6$ & finam.rugosa & $40-55$ & 40 & $5-5$ & - \\
\hline A.sclerotiicarbonar & ius $4,8-9,5$ & finam.espinosa & $45-90$ & 33 & $0-0$ & - \\
\hline A. sclerotioniger & $4,5-6-4$ & finam.rugosa & $30-50$ & 36 & $4-2$ & + violeta,esclerocios \\
\hline A. tubingensis & $3-5$ & finam.espinosa & $40-80$ & 40 & $1-1$ & - \\
\hline A. vadensis & $3-4$ & lisos & $25-35$ & 40 & $5-5$ & - \\
\hline
\end{tabular}

* El médio de cultivo agar creatina sucrosa (CREA) permite ver el crecimiento y la producción de ácido (es de color violeta púrpura y cambia al amarillo con la producción de ácido). Los números del 1 al 5 en forma gradual, indican el tamaño del halo o de la colonia, siendo el 1 el más pequeño; el cero indica que no hay crecimiento.

La composición del medio es: Creatina (1H2O) 3 g; Sucrosa 30 g; KCL 0,5 g; MgSO4.7H2O 0,5 g; FeSO4.7H2O 0,01g; K2HPO4.3H2O 1,3 hasta 1,6 g; Púrpura de bromocresol 0,05 g; agar 15 g; Agua destilada 1000 mL. pH.final $8 \pm 0,2$, ajustarlo después de autoclavarlo. 


\section{REFERENCIAS}

Abliz, P.; Horie,Y.; Hui, Y.; Nishimura, K.; Li, R. (2001). New and interesting species of Eurotium from Chinese soil. Mycoscience 42: 289-294

Al-Musallan, A.(1980). A revision of the black Aspergillus species. Ph.D Thesis. Utrecht, Nederlands, Univ. Utrecht.

Balajee, S.A.; Gribskov, J.L.; Hanley, E.; Nickle, D.; Marr, K.A. (2005). Aspergillus lentulus sp. nov., a new sibling species of A. fumigatus. Eukaryotic Cell 4:625-632

Balajee, S.A.; Nickle, Varga, J \& Marr, K.A (2006). Molecular studies reveal frequent misidentification of Aspergillus fumigatus by morphotyping. Eukaryotic Cell 5:1705-1712

Balajee, S.A.; Houbraken, J.; Verweij, P.E.; Hong, S-B.; Varga, J.; Samson, R.A. (2007). Aspergillus species identification in the clinical setting. Studies in Mycology 59:39-46

Bennett, J.W.\& Klich, M.A. (2003). Mycotoxins. Clinical Microbiology Review 16:497-516

Chu, K.H.; Li, C.P. \& Qi, J. (2006). Ribosomal RNA as molecular barcodes: a simple correlation analysis without sequence alignment. Bioinformatics 22:1690-1701

Christensen, M.(1981).A synoptic key and evaluation of species in the Aspergillus flavus grup. Mycologia 73:1056-1084

Christensen, M.(1982). The Aspergillus ochraceous grup.:two new specie from western soils and synoptic key. Mycologia $74: 210-225$

De- Wei Li \& Zhao, G. (2007). Goidanichiella cylindrospora sp. nov. from Connecticut USA. Mycotaxon 101:41-45

Dyer, P.S.\& Paoletti, M. (2005). Reproduction in Aspergillus fumigatus: sexuality in a supposedly asexual species? Medical Mycology 43:S7-S14

Frisvald, J.C.\& Thrane, U. (1993). Liquid Chromatography of mycotoxins. Journal Chromoatography Library 54:253-372

Frisvad, J.C.; Frank, J.M.; Houbraken, J.A.M.P.; Kuijpers, A.F.A.; Samson, R.A. (2004). New ochratoxin A producing species of Aspergillus section Cirumdati. Studies in Mycology $50: 23-43$

Frisvad, J.C.; Skouboe, P.\& Samson, R.A. (2005). Taxonomic comparison of three different groups of aflatoxin producers and a new efficient producer of Aflatoxin B, strigmatocistin and 2-O mathylsterigmatocystin. Aspergillus rambelli sp. Nov. Systematic and Applied Microbiology 28:442453

Frisvad, J.C. \& Samson, R.A. (2000). Neopetromyces gen. nov. and an overview of teleomorphs of Aspergillus subgenus Circumdati. Studies in Mycology 45:201-07

Frisvald, J.C.;Anderson, B.\& Thrane, U. (2007). The use of secondary metabolite profiling in chemotaxonomy of filamentous fungi. Mycological Reserch DOI 10/1016/j. mycres 08.018

Gams, W.; Christensen, M.; Onions, A.H.; Pitt, J.I.; Samson, R.A. (1985). Infrageneric taxa of Aspergillus. In: Advances in Penicillium and Aspergillus Systematics. Samson RA, Pitt JI, eds.. New York: Plenum Press. pp. 55-62
Geiser, D.M. (2004). Practical molecular taxonomy of fungi. In: Advances in Fungal Biotechnology for Industry, Medicine and Agriculture. Lange, L. \& Tkacz, J. eds.New York: Kluwer Academic Publishers. pp. 1-12

Hamari, Z.; Kevei, F.; Kovács, E.; Varga, J.; Kozakiewicz, Z.; Croft, J.H. (1997). Molecular and phenotypic characterization of Aspergillus japonicus and Aspergillus aculeatus strain with special regard to their mitocondrial DNA polymorphisms. Antonie Van. Leeuwenhoek. 72:337-347

Hong, S-B.; Go, S-J.; Shin, H-D.; Frisvad.; J.C.; Samson, R,A. (2005). Polyhphasic taxonomy of Aspergillus fumigatus and related species. Mycologia 97:1316-1329

Hong, S-B.; Cho, H-S.; Shin, H-D.; Frisvad, J.C.; Samson, R,A. (2006). Novel Neosartorya species isolated from soil in Korea. International Journal of Systematic and Evolutionary Microbiology 56:477-486

Hong,S-B.; Shin, H-D.; Hong, J-B.; Frisvad, J.C.; Nielsen, P.V.; Varga, J.; Samson, RA (2007).New taxa of Neosartorya and Aspergillus in Aspergillus section Fumigati.Antonie van Leeuwenhoek 93:87-98

Houbraken, J.; Varga, J.; Due, M.; Frisvad, J.C.; Samson, R.A. (2007). Polyphasic taxonomy of Aspergillus section Usti. Studies in Mycology 59:107-128

Horn, B,W. (1997). Aspergillus caelatus a new species in section Flavi, Mycotaxon 61:185-191

Ito, Y.; Peterson, S.W.; Wicklow, DT.\& Goto, T. (2001). Aspergillus pseudotamarii, a new aflatoxin producing species in Aspergillus section Flavi. Mycological Research 105:233-239

Kevei, F.; Hamari, Z.; Varga, J.; Kozakiewicz, Z.; Croft, J.H. (1996). Molecular polymorphism and phenotypic variation in Aspergillus carbonarius. Antonie Van Leeuwenhoek 70:5966

Klich, M. (2002). Identification of common Aspergillus species CBS Biodiversity Series, Utrecht.

Kozakievicz, Z. (1989). Aspergillus species in stored products. Mycological Papers 161.

Lass-Flörl, C.; Grif, K.\& Kontoyiannis,D.P. (2007). Molecular typing of Aspergillus terreus isolates collected in Houston, Texas, and Insbruck, Austria: Evidence of great genetic Diversity. J.Clin Microbiol. 45:2686-2690

McClenny, N. (2005).Laboratory detection and identification of Aspergillus species by microscopic observation and culture: the traditional approach. Medical Mycology Supplement 1, 43: S125-S128

Min, X. J. \& Hickey, D.A. (2007). Assessing the effect of varying sequence length on DNA barcoding of fungi. Molecular Ecology Notes 7:365-373

Okuda,T.; Klich, M.A.; Seifert, K.A. \& Ando,K. (2000). Media and incubation effects on morphpological characteristics of Penicillium and Aspergillus. In: Integration of modern taxonomic methods for Penicillium and Aspergillus classification (Eds. Samson, R.A. \& Pitt, J.I.) Harwood Academic Plublishers, U.K. pp.83-99

Paoletti, M.; Rydholm, C.; Schwier, E.U.; Anderson, M.J.; 
Szakács, G.; Lutzoni, F.;Debeaupuis, J.P.; Latge, J.P.; Denning, D.W. Dyer, P.S. (2005). Evidence for sexuality in the opportunistic fungal pathogen Aspergillus fumigatus. Current Biology 15:1242-1248

Perrone, G.; Susca, A.; Cozzi, G.; Ehrich, K.; Varga, J.; Frisvad, J.C.; Meijer, M.; Noonim, P.; Mahakamchanakul, W.; Samson, R.A. (2007). Biodiversity of Aspergillus species in some important agricultural products. Studies in Mycology 59:53-66

Perrone, G.; Varga, J.; Susca, A.; Frisvad, J.C.; Stea, G.; Kocsubé, S.; Tóth, B.; Kozakiewicz, Z.; Samson, R.A. (2008). Aspergillus uvarum sp. nov., an uniseriate black Aspergillus species isolated from grapes in Europe. International J. of Systematic and Evolutionary Microbiology 58:1032-1039

Peterson, S.W. (2000). Phylogenetic relationships in Aspergillus based on rDNA sequence analysis. In: Integration of Modern Taxonomic Methods for Penicillium and Aspergillus Classification, Samson RA, Pitt JI, eds. Amsterdam: Harwood Academic Publishers pp.323-356

Peterson, S.W. (2008). Phylogenetic analysis of in Aspergillus species using DNA sequencse from fpur loci. Mycologia 100:205226

Peterson, S.W.; Ito, Y.; Horn, B.W.\& Goto, T. (2001). Aspergillus bombycis, a new aflatoxigenic species and genetic variation in its sibling species, A. nomius. Mycologia 93:689703

Peterson, S.W.; Varga, J.; Frisvald, J.C.; Samson, R.A (2008). Phylogeny and subgeneric taxonomy of Aspergillus: In Varga, J.\& Samson, R,A.(eds.. Wageningen Academic Publishers, Wageningen, The Nederlands. pp.33-56

Pildain, M.B.; Frisvad, J.C.; Vaamonde, G.; Cabral, D.; Varga, J.; Samson, R.A. (2008). Two new aflatoxin producing Aspergillus species from Argentinean peanuts. International J. of Systematic and Evolutionary Microbiology 58:725-735

Pitt, J.I.; Hocking, A.D. \& Glenn, D.R. (1983).An improved medium for the detection of Aspergillus flavus and A.parasiticus. J.Appl.Bact. 54:109-114

Pitt, J.I. \& Hocking, A.D.(1997). Fungi and food spoilage. Academic Press $2^{\text {nd }}$ ed.

Pitt. J.I.; Samson, R.A.\& Frisvad, J.C. (2000). List of accepted species and their teleomorphs in the family Trichocomaceae. In: Integration of Modern Taxonomic Methods for Penicillium and Aspergillus. Samson RA, Pitt JI, eds. Amsterdam: HarwoodAcademic Publishers, pp. 9-47

Powell, K.A.; Renwick, A.\& Peberdy. J.F. (eds).(1994) The Genus Aspergillus: From taxonomy and genetics to industrial application, New York, Plenum Press,

Pringle, A.; Baker, D.M.; Platt, J.L.; Wares, J.P.; Latge, J.P.; Taylor, J.W. (2005). Cryptic speciation in the cosmopolitan and clonal human pathogenic fungus Aspergillus fumigatus. Evolution 59:1886-1899

Raper, K.B.\& Fennell, D.I. (1965). The Genus Aspergillus. Baltimore: Williams \& Wilkins.

Samson, R.A. (1979). A compilation of the Aspergilli described since1965. Stud. Mycol.18:1-38

Samson, RA. \& Gams, W. (1985). Typification of the species of Aspergillus and associated teleomorphs. In: Advances in Penicillium and Aspergillus Systematics. Samson, R.A. \& Pitt J.I., eds. New York: Plenum Press, pp. 143-154

Samson, R.A. (1992). Current taxonomic schemes of the genus Aspergillus and its teleomorphs. In: Bennett JW, Klich MA (eds).Aspergillus: Biology and Industrial Applications. Boston: Butterworth-Heinemann, pp. 355-390.

Samson, R.A.(1993). Taxonomy current concepts of Aspergillus systematics. In: Smith, J.E. (ed.). Aspergillus Biotechnology Handbooks, vol. 7. New York: Plenum Press, pp. $1-22$

Samson, R.A. (2000). List of names of Trichocomaceae published between 1992 and 1999. In: Integration of Modern Taxonomic Methods for Penicillium and Aspergillus. Samson, R.A. \& Pitt J.I., eds. Amsterdam: Harwood Academic Publishers, pp. $73-79$

Samson, R.A. \& Pitt, J.I. (eds).(2000). Integration of Modern Taxonomic Methods for Penicillium and Aspergillus Classification . Amsterdam:Harwood Academic Publishers.

Samson, R.A.; Houbraken, J.A.M.; Kuijpers, A.F.A.; Frank, J.M.; Frisvald, J.C. (2004). New ochratoxin A on sclerotium producing species in Aspergillus section Nigri Studies in Mycology $50: 45-51$

Samson, R.A.; Hoekstra, E. S. \& Frisvad, J.C. (2004). Introduction to food-and airborne fungi. CBS. Utrecht, The Netherlands.

Samson, R.A.; Hong, S-B.\& Frisvad, J.C. (2006). Old and new concepts of species differentiation in Aspergillus. Medical Mycology 44:S133-S148

Samson, R.A.; Hong, S-B.; Peterson, S.W.; Frisvad, J.C.; Varga, J.(2007). Polyphasic taxonomy of Aspergillus section Fumigati and its teleomoorph Neosartorya. Studies in Mycology 59:147-207

Samson, R.A.; Noonim, P.;Medijer, M.;Houbraken,J.; Frisvad, J.C.; Varga, J.(2007b). Diagnostic tools to identify black aspergilli. Studies in Mycology 59:129-145

Samson R.A. \& Varga. J. (2007). Aspergillus systematics in the genomic era. Studies in Mycology 59:1-206

Seifert, K.A.; Samson, R.A.; Dewaard, J.R.; Houbraken, J.; Levesque, C.A.; Moncalvo, J.M.; Louis-Seize, G.; Hebert, P.D. (2007). Prospects for fungus identification using CO1 DNA barcodes, with Penicillium as a test case. Proceedings of the National Academy of Sciences U.S.A. 104:39013906

Sepúlveda, C. O. \& Piontelli, E. (2005). Poblaciones de Aspergillus en semillas de maíz y soja de importación argentina: Enfasis en la sección Flavi. Boletín Micológico 20:41-55

Serra, R.;Cabanes, F.J.; Perrone, G.; Castella, G.; Venancio, A.; Mule, G.; Kozakiewicz, Z. (2006). Aspergillus ibericus: a new species of section Nigri isolated from grapes. Mycologia 98:295-306

Smedsgaard, J. (1997). Micro-scale extraction procedure for standarized screening of fungal metabolite production in culture. Journal Chromatography A 760:264-270

Takada, M.; Horie, Y. \& Abliz, P. (2001). Two new heterothallic Neosartorya from African soil. Mycoscience 
$42: 361-367$

Taylor, J.W.; Jacobson, D.J.; Kroken, S.; Kasuga, T.; Geiser, D.M.; Hibbett, D.S.; Fisher, M.C. (2000). Phylogenetic species recognition and species concepts in fungi. Fungal Genetics and Biology 31:21-32

Thom, C. \& Church, M.B. (1926). The aspergilli. Baltimore: Williams \& Wilkins.

Thom, C. \& Raper, K.B. (1945). Manual of the aspergilli. Baltimore: Williams \& Wilkins.

Varga, J.; Juhász, A.; Kevei, F. \& Kozakievicz, Z. (2004). Molecular diversity of agriculturally important Aspergillus species. Europ. J. Plant Pthol. 110:627-649

Varga, J.; Tóth, B.; Kocsubé, S.; Farkas ,B.; Szakács,G.; Téren, J.; Kozakiewicz, Z. (2005). Evolutionary relationships among Aspergillus terreus isolates and their relatives. Antonie Van Leeuwenhoek 88:141-150
Varga, J.; Kocsubé, S.; Tóth, B.; Frisvad, J.C.; Perrone, G.; Susca, A.; Meijer, M.; Samson, R.A. (2007). Aspergillus brasiliensis sp. nov., a biseriate black Aspergillus species with world-wide distribution. International Journal of Systematic and Evolutionary Microbiology 57:1925-1932

Varga, J.; Due, M.; Frisvad, J.C.; Samson, R.A. (2007b). Taxonomic revision of Aspergillus section Clavati based on molecular, morphological and physiological data. Studies in Mycology 59:89-106

Varga, J.; Frisvad, J.C.; Samson, R.A. (2007c).Polyphasic taxonomy of Aspergillus section Candidi based on molecular, morphological and physiological data. Stud.in Mycol. 59:75-88 